
Not for reproduction, distribution or commercial use.

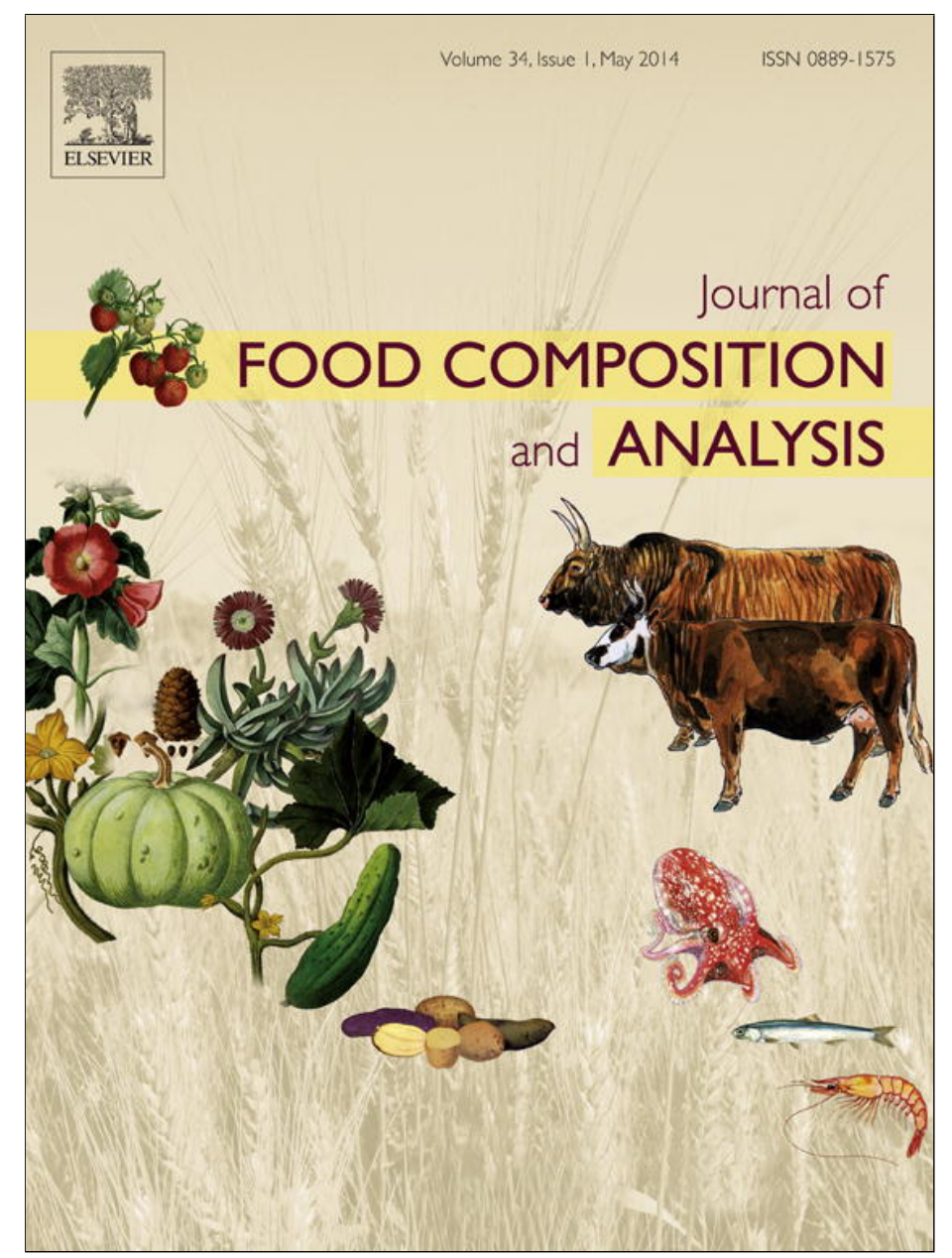

This article appeared in a journal published by Elsevier. The attached copy is furnished to the author for internal non-commercial research and education use, including for instruction at the authors institution and sharing with colleagues.

Other uses, including reproduction and distribution, or selling or licensing copies, or posting to personal, institutional or third party websites are prohibited.

In most cases authors are permitted to post their version of the article (e.g. in Word or Tex form) to their personal website or institutional repository. Authors requiring further information regarding Elsevier's archiving and manuscript policies are encouraged to visit: 


\title{
Adding oenological tannin vs. overripe grapes: Effect on the phenolic composition of red wines
}

\author{
C. Alcalde-Eon, I. García-Estévez, R. Ferreras-Charro, J.C. Rivas-Gonzalo, R. Ferrer-Gallego, \\ M.T. Escribano-Bailón*
}

Grupo de Investigación en Polifenoles, Unidad de Nutrición y Bromatología, Facultad de Farmacia, Universidad de Salamanca, Campus Miguel de Unamuno, E 37007 Salamanca, Spain

\section{A R T I C L E I N F O}

\section{Article history:}

Received 22 November 2012

Received in revised form 27 October 2013

Accepted 12 January 2014

\section{Keywords:}

Food analysis

Food composition

Winemaking practices

Tempranillo red wine

HPLC-DAD-MS ${ }^{n}$

Climate change

Oenological tannin

Flavanols

Phenolic acids

Anthocyanins

CIELAB

\begin{abstract}
A B S T R A C T
The effects on the phenolic composition (flavanols, phenolic acids and anthocyanins) and on CIELAB colour parameters of two different oenological practices (adding oenological tannin, using overripe grapes), whose purpose is to compensate wine quality deficiencies, have been evaluated in red wines made from Tempranillo grapes in two consecutive vintages. Both the addition of oenological tannin and the use of overripe grapes generally increased hydroxycinnamic acids and pigment contents. However, the effect of the former was noticeable above all in early stages of winemaking and ageing, whereas the effect of the latter was observable in late stages of ageing. In general, flavanol content increased in wines treated with oenological tannin, and decreased in wines made from overripe grapes in relation to control wines. Colour differences $\left(\Delta E_{\mathrm{ab}}^{*}\right)$ between control and treated wines were in some stages higher than 3 , indicating that the colour modifications caused by both treatments can be detectable by the human eye. Results showed that the addition of the oenological tannin to wine will be useful to address deficiencies in flavanol and pigment contents, whereas the use of overripe grapes will be useful when colour stabilization is required.
\end{abstract}

(c) 2014 Elsevier Inc. All rights reserved.

\section{Introduction}

The increase in the frequency of extremely hot days and the alteration of the rainfall patterns associated with global climate change are going to have an important impact in agriculture. Vineyards are also very sensitive to climate change but the effects of these changes on viticulture have been and are likely to be highly variable not only from a geographical point of view but also for the different grape varieties (Jones et al., 2005). Although these changes might cause short-term benefits in terms of more consistent and higher-quality production, viticultural and oenological strategies will be needed to reduce the long-term impact on wine quality (Jones et al., 2005; Ramos et al., 2008).

The effects of the climate change on grape composition and the consequences on wine quality have been recently reviewed by Mira de Orduña (2010). The concentrations of several grape

\footnotetext{
* Corresponding author. Tel.: +34 923 294537; fax: +34 923294515. E-mail addresses: a51711@usal.es (C. Alcalde-Eon), igarest@usal.es (I. García-Estévez), rferrerasch@usal.es (R. Ferreras-Charro), jcrivas@usal.es (J.C. Rivas-Gonzalo), rauferga@usal.es (R. Ferrer-Gallego), escriban@usal.es (M.T. Escribano-Bailón).
}

metabolites are clearly affected by temperature and it has been observed that higher temperatures during berry development may increase $\mathrm{pH}$ and sugar concentration and affect the levels of flavonoids. In addition, it has been reported that harvest dates have advanced, especially in the last $10-30$ years (Mira de Orduña, 2010).

Traditionally, grapes are harvested at technological maturity, i.e. when the grapes reach the optimal weight, sugar concentration, $\mathrm{pH}$, total acidity, etc. in light of the particular wine being produced. In addition the quality of a wine also depends on polyphenol content, which changes as grape ripen. Thus, over the recent years not only technological maturity has been taken into account for the selection of harvest date but also phenolic ripeness, which refers, above all, to the contents of anthocyanins and tannins. Generally, after veraison the phenolic content of grape skin increases. Unlike skin tannins, anthocyanins reach a maximum and then they begin to decrease (Ribéreau-Gayon et al., 2000).

Seed tannins, on the contrary, tend to decrease or remain more or less constant as grapes ripen (Kennedy et al., 2000; RibéreauGayon et al., 2000). Ideally, technological maturity and phenolic maturity should coincide, but environment and climatic conditions may cause a delay between them. The advancement of harvest date, which is related to earlier technological maturity, can 
increase the delay between these two kinds of maturity and, as a consequence, grapes collected at technological maturity might possess an inadequate phenolic composition, and the wines made from them might be too bitter or/and astringent and poor in anthocyanins. Furthermore, previous studies carried out in our laboratory (Ferrer-Gallego et al., 2012) have shown that the phenolic maturity patterns of grape skins and seeds are different and that they are differently affected by climatic conditions.

In order to obtain quality wines all these aspects have to be taken into account and harvest date should be a compromise date between technological and phenolic ripeness. However, it seems that global climate change is going to increase the delay between them (Mira de Orduña, 2010) making it even more difficult to choose the appropriate harvest date for the desired type of wine. Different approaches have been proposed to solve this problem. Adding exogenous tannins either in the form of grape seeds or in the form of commercial oenological tannins and the use of overripe (from a technological point of view) grapes, among others, aim at improving the phenolic quality of the wines and have been employed in winemaking based on practical experience.

However, until recently the effects of these techniques on phenolic composition have not been studied. Some of the positive effects of using oenological tannins that are reported by tannin suppliers are the improvement of wine colour and its stability, oxidative protection, and flavour and mouthfeel improvement. Recent studies (Bautista-Ortín et al., 2007) have shown that the effect of adding these oenological tannins can change from year to year and that they depend on grape characteristics at the moment of harvest. Furthermore, it has been reported that at the concentration recommended by tannin suppliers no significant differences with regard to colour properties could be observed between the tannin-treated wines and the control wines, and that tannin addition had only a minor effect on perceived astringency (Parker et al., 2007). Higher concentrations than those recommended can even produce a negative and measurable impact on wine sensory characteristics (Harbertson et al., 2012).

With respect to overripe grapes, winery experience shows that the wines made from these grapes possess more stable colour and more intense purple hues than those made from less mature grapes (Pérez-Magariño and González-San José, 2006). However, several aspects have to be taken into account. Not only does the evolution of phenolic compound levels need to be considered as grapes ripens but the changes in the extractability of these compounds must also be considered. In general, extraction of phenolic compounds from skins seems to be promoted as grapes ripen, due to the changes in the cell wall (Canals et al., 2005; Hernández-Hierro et al., 2012; Ortega-Regules et al., 2006; Río Segade et al., 2008). On the other hand, the evolution of grape seed cell wall composition and structure during ripening seems to decrease the extractability of these compounds from seeds (Cadot et al., 2006). However, longer maceration times and higher ethanol contents may facilitate the extraction of seed proanthocyanidins (Canals et al., 2005; Gil et al., 2012; González-Manzano et al., 2004) and compensate for the decrease in their extractability occurring during ripening. In addition, the evolution of phenolic content and extractability during ripening may differ from one grape variety to another (Ortega-Regules et al., 2006; Río Segade et al., 2008). In order to determine the utility of these different oenological practices in overcoming the deficiencies related to the delay between technological and phenolic ripeness, it is thus necessary to carry out specific studies for each grape variety.

Detrimental effects on grapevine growth and development and on wine yields and quality parameters have been projected for southern Europe because of increasing dryness and cumulative thermal effects during the growing season (Malheiro et al., 2010). In fact, mean temperatures in Spain during the 20th century showed a general increase, with a magnitude greater than the global average, and rainfall showed a downward trend. The temperature increase projected for the Iberian Peninsula is $0.4{ }^{\circ} \mathrm{C} /$ decade in winter and 0.6 or $0.7{ }^{\circ} \mathrm{C}$ /decade in summer. Concerning rainfall, a generalized tendency towards less annual accumulated rainfall has been projected with an important reduction in spring (Moreno-Rodríguez, 2005). From these data it can be deduced that Spanish vineyards are going to be especially sensitive to global climate change. Among red grape varieties grown in Spain, Tempranillo (Vitis vinifera L.) is the most cultivated (MAGRAMA, 2009). Studies on the impact of predicted climate changes on Tempranillo grape quality have been recently carried out in greenhouse experiments and have revealed that these changes (elevated $\mathrm{CO}_{2}$, high temperature and partial irrigation) will affect phenology and berry quality (Salazar-Parra et al., 2010).

The objective of the present work was to evaluate the effect of two different oenological practices (adding oenological tannin during alcoholic fermentation or use of overripe grapes) on phenolic composition (flavanols, hydroxycinnamic acids and anthocyanins) and colour parameters in wines made from Vitis vinifera L. cv Tempranillo from D.O. Ribera de Duero (Spain). The final goal was to assess the usefulness of these oenological practices in lessening the negative effects on wine quality associated with the delay between technological and phenolic ripeness which are related, in turn, to global climate change.

\section{Materials and methods}

\subsection{Samples}

Three different wines elaborated in 2 consecutive vintages (2009 and 2010) by Bodegas La Horra S.L. (D.O. Ribera de Duero, La Horra, Spain) from Vitis vinifera L. cv. Tempranillo grapes were analysed. Two of these wines were elaborated from grapes collected at two different ripeness states: technological ripeness (Control wine) and 13 days after technological ripeness (Overripe wine). The third wine (Tannin wine) was elaborated from the same grapes as Control wine (collected at technological ripeness), to which oenological tannin (supplied by Laffort España, Errenteria, Guipúzcoa, Spain) was added twice during alcoholic fermentation in a dose of $15 \mathrm{~g} / \mathrm{hL}$ each time, as recommended by manufacturer. The oenological tannin added was an extract from natural sources which was mainly constituted by proanthocyanidins $(58.8 \%$, with catechins and procyanidins representing by themselves $42 \%(25.7 \%$ monomers, $11.7 \%$ dimers and $4.6 \%$ trimers) of the oenological tannin), oak ellagitannins (11.2\%) and hydroxybenzoic acids (7.5\%).

Maceration and alcoholic fermentation were carried out in a stainless steel tank $(1200 \mathrm{~L})$. At the end of alcoholic fermentation, wines were transferred into new medium-toasted French oak barrels $(225 \mathrm{~L})$, where malolactic fermentation took place and where the wines were aged. All the barrels were manufactured by Societé Seguin Moreau et Compagnie (Merpins, France) from naturally seasoned oak wood (24 months of seasoning). During barrel ageing three rackings were performed (between points 5 and 6,8 and 9 and 10 and 11). After barrel ageing (for ca. 14 months in 2009 vintage and ca. 12 months in 2010 vintage), wines were bottled and aged in bottle for 6 months.

Wine samples were collected at different moments during winemaking and ageing from the alcoholic fermentation to 6 months after bottling (Table 1 ).

\subsection{HPLC-DAD-ESI/MS ${ }^{\mathrm{n}}$ analyses}

Analyses were performed in triplicate in a Hewlett-Packard 1100 series liquid chromatograph (Agilent Technologies, Waldbronn, Germany). The mass spectrometer was connected to HPLC 
Table 1

Sampling points and their correspondence with winemaking and ageing stages. In 2010 vintage, sampling points " 7 days after end of MLF" and "Before 1st racking" (points 4 and 5) were coincident in time as well as points 7 and 8 (" 3 months after end of MLF" and "Before 2nd racking") and only one sample per pair of sampling point was collected. MLF: Malolactic fermentation. d: days, m: months.

\begin{tabular}{|c|c|c|c|}
\hline \multicolumn{2}{|c|}{ Sampling point } & \multicolumn{2}{|l|}{ Time } \\
\hline & & \multirow{2}{*}{$\begin{array}{l}2009 \text { Vintage } \\
\text { od }\end{array}$} & \multirow{2}{*}{$\begin{array}{l}2010 \text { Vintage } \\
\text { Od }\end{array}$} \\
\hline 0 & Density $1000 \mathrm{~g} / \mathrm{L}$ & & \\
\hline 1 & Devatting & $4 d$ & $4 d$ \\
\hline 2 & MLF & - & $1 \mathrm{~m} \mathrm{7d}$ \\
\hline 3 & End of MLF & $2 \mathrm{~m}$ & $2 \mathrm{~m} 7 \mathrm{~d}$ \\
\hline 4 & 7 days after end of MLF & $2 \mathrm{~m} 7 \mathrm{~d}$ & - \\
\hline 5 & Before 1st racking & $3 m$ & $2 \mathrm{~m} 15 \mathrm{~d}$ \\
\hline 6 & 7 days after 1 st racking & $3 \mathrm{~m} \mathrm{7d}$ & $2 \mathrm{~m} \mathrm{21d}$ \\
\hline 7 & 3 months after end of MLF & $6 m$ & - \\
\hline 8 & Before 2nd racking & $7 \mathrm{~m}$ & $5 \mathrm{~m} 15 d$ \\
\hline 9 & 7 days after 2 nd racking & $7 \mathrm{~m} \mathrm{7d}$ & $5 \mathrm{~m} \mathrm{21d}$ \\
\hline 10 & Before 3rd racking & $11 \mathrm{~m}$ & - \\
\hline 11 & 7 days after 3rd racking & $11 \mathrm{~m} \mathrm{7d}$ & $8 \mathrm{~m} \mathrm{21d}$ \\
\hline 12 & 3 months after bottling & $17 \mathrm{~m}$ & $15 \mathrm{~m} 15 \mathrm{~d}$ \\
\hline 13 & 6 months after bottling & $20 \mathrm{~m}$ & $18 \mathrm{~m} 18 \mathrm{~d}$ \\
\hline
\end{tabular}

system via the DAD cell outlet. MS detection was performed in a API 3200 Qtrap (Applied Biosystems, Darmstadt, Germany) equipped with an ESI source and a triple quadrupole-ion trap mass analyser that was controlled by Analyst 5.1 software. Zero grade air served as nebulizer gas (GS1) and turbo gas (GS2) for solvent drying. Nitrogen served as curtain (CUR) and collision gas (CAD).

\subsubsection{Analysis of anthocyanins and derivative pigments}

Wine samples were diluted $(1 / 5)$ with acidified water $(\mathrm{pH} 1, \mathrm{HCl})$ and filtered through a $0.45 \mu \mathrm{m}$ Millex syringe-driven filter unit (Millipore Corporation, Bedford, MA, USA) before HPLC-DAD-MS analysis. An AQUA C18 reversed-phase, $5 \mu \mathrm{m}, 150 \mathrm{~mm} \times 4.6 \mathrm{~mm}$ column (Phenomenex ${ }^{\mathbb{B}}$, Torrance, CA, USA) thermostatted at $35{ }^{\circ} \mathrm{C}$ was used. The HPLC-DAD conditions were previously employed with satisfactory results in our laboratory in the analysis of wine samples (Alcalde-Eon et al., 2006). Detection was carried out at $520 \mathrm{~nm}$ as the preferred wavelength. Spectra were recorded from 220 to $600 \mathrm{~nm}$. Analyses were performed in triplicate.

MS analysis was carried out in positive mode $\left(\mathrm{ESI}^{+}\right)$. Settings used were optimized by direct infusion of a malvidin 3-O-glucoside solution: declustering potential (DP) $41 \mathrm{~V}$, entrance potential (EP) $7.5 \mathrm{~V}$, ion spray voltage (IS) $5000 \mathrm{~V}$, GS1 $40 \mathrm{psi}$, GS2 $50 \mathrm{psi}\left(600^{\circ} \mathrm{C}\right)$, CUR 20 psi, and CAD was set as "High". Both quadrupoles were set at unit resolution. Mass method consisted of three mass experiments: full mass analysis (EMS mode, collision energy (CE) $10 \mathrm{~V}$ ), $\mathrm{MS}^{2}$ analysis (EPI mode, CE $25 \mathrm{~V}$ ) and $\mathrm{MS}^{3}$ analysis (CE $30 \mathrm{~V}$, excitation energy (AF2) $50 \mathrm{~V}$ ). Spectra were recorded between $\mathrm{m} / \mathrm{z} 150$ and 1100 .

Twenty-three anthocyanins and derivative pigments were determined: 5 anthocyanin 3-O-glucosides, 5 anthocyanin 3-Oacetylglucosides, 8 anthocyanin 3-O-cumaroylglucosides, 3 flavanolanthocyanin direct condensation products, the $A$-type vitisin of malvidin 3-O-glucoside and the vinylphenol-malvidin 3-O-glucoside pyranoanthocyanin.

\subsubsection{Analysis of flavanols and phenolic acids}

Wine sample was fractionated prior to HPLC-DAD-MS analysis with the objective of eliminating the anthocyanins. Fractionation was carried out following the procedure reported by GonzálezManzano et al. (2006): $1 \mathrm{~mL}$ of wine diluted (1:1) with $0.1 \mathrm{~N} \mathrm{HCl}$ was loaded on an Oasis ${ }^{\circledR}$ MCX cartridge (Waters Corporation, Milford, MA, USA) previously conditioned with $2 \mathrm{~mL}$ of methanol (Prolabo, VWR International, Fontenay-sous-Bois, France) and $2 \mathrm{~mL}$ of water. After washing with water ( $4 \mathrm{~mL})$, flavanols and phenolic acids were eluted with $8 \mathrm{~mL}$ of methanol. The eluate was concentrated under vacuum and redissolved in $500 \mu \mathrm{L}$ of water. An aliquot was filtered through a $0.45 \mu \mathrm{m}$ Millex syringe-driven filter unit and analysed by HPLC-DAD-MS using a Spherisorb ${ }^{\mathbb{R}}$ S3 ODS-2 C18 reversed-phase, $3 \mu \mathrm{m}, 150 \mathrm{~mm} \times 4.6 \mathrm{~mm}$ column (Waters, Corporation, Milford, MA, USA) thermostatted at $25^{\circ} \mathrm{C}$. HPLC-DAD conditions have been previously employed with satisfactory results in our laboratory in the analysis of these compounds (García-Marino et al., 2006). Detection was carried out at $280 \mathrm{~nm}$ (flavanols) and $330 \mathrm{~nm}$ (phenolic acids) as the preferred wavelengths. Spectra were recorded from 220 to $600 \mathrm{~nm}$. Analyses were performed in triplicate.

MS analysis was carried out in negative mode $\left(\mathrm{ESI}^{-}\right)$. Settings used were optimized by direct infusion of a catechin (SigmaAldrich, St Louis, MO, USA) solution: DP $-40 \mathrm{~V}$, EP $-7 \mathrm{~V}$, IS $-4000 \mathrm{~V}, \mathrm{GS} 140 \mathrm{psi}, \mathrm{GS} 230 \mathrm{psi}\left(400^{\circ} \mathrm{C}\right)$, CUR $20 \mathrm{psi}$, and CAD was set as "Medium". Both quadrupoles were set at unit resolution. Mass method consisted of two mass experiments: full mass analysis (EMS mode, CE $-20 \mathrm{~V}$ ) and $\mathrm{MS}^{2}$ analysis (EPI mode, CE $-25 \mathrm{~V}$ ). Spectra were recorded between $\mathrm{m} / \mathrm{z} 100$ and 1700 .

Seventeen flavanols were determined: 3 monomers (catechin, epicatechin and gallocatechin), 10 procyanidins (6 dimers, 3 trimers and 1 galloylated dimer) and 4 prodelphinidins ( 2 dimers and 2 trimers).

Nine phenolic acids were determined: 8 hydroxycinnamic acids and their tartaric esters and 1 hydroxybenzoic acid (gallic acid).

\subsection{Colorimetric measurements}

Wine $\mathrm{pH}$ was standardized to 3.6 with $0.1 \mathrm{~N} \mathrm{HCl}$ (Panreac, Castellar del Vallès, Spain). Absorption spectra (190-1100 nm) were recorded using a Hewlett-Packard UV-vis HP 8453 (Agilent Technologies, Waldbronn, Germany) spectrophotometer in $2 \mathrm{~mm}$ path length quartz cells. The analysis of colour was made only from the visible spectra (380-770 nm) data, using the CIE 1964 standard observer ( $10^{\circ}$ visual field) and the CIE standard illuminant D65 as references. CIELAB colour parameters $\left(L^{*}, a^{*}, b^{*}, C_{\mathrm{ab}}^{*}\right.$ and $\left.h_{\mathrm{ab}}\right)$ were calculated using the software CromaLab ${ }^{\circledR}$ (Heredia et al., 2004). Colour differences between Control and treated wines were determined by means of the CIELAB colour difference formula:

$\Delta E_{\mathrm{ab}}^{*}=\left(\left(\Delta L^{*}\right)^{2}+\left(\Delta a^{*}\right)^{2}+\left(\Delta b^{*}\right)^{2}\right)^{1 / 2}$

\subsection{Chemometric techniques}

An unsupervised pattern recognition method, principal components analysis (PCA) was used for data analysis. PCA was applied from the correlation matrix of the original variables. The total variables used were 20 , corresponding to detailed phenolic composition: 5 anthocyanins and derivative pigments (total anthocyanin 3-Oglucosides, total anthocyanin 3-O-acylglucosides, Flavanol-anthocyanin direct condensation products, A-type vitisin of Malvidin 3-Oglucoside and Vinylphenol-Malvidin 3-O-glucoside pyranoanthocyanin), 5 flavanols (Total catechins and procyanidins, Sum of catechin and epicatechin, dimeric procyanidins, trimeric procyanidins and total gallocatechin and prodelphinidins), 5 phenolic acids (gallic, caftaric, caffeic, coutaric and p-coumaric acids) and 5 CIELAB colour parameters (Lightness $\left(L^{*}\right)$, Chroma $\left(C_{\mathrm{ab}}^{*}\right)$, hue $\left(h_{\mathrm{ab}}\right)$, coordinate $a$ and coordinate $b$ ). Statistica 6.0 software (StatSoft, Tulsa, OK, USA) was used to carry out the statistical analysis.

\section{Results and discussion}

\subsection{Flavanols}

\subsubsection{Catechins and procyanidins}

Differences in the total content of these compounds (sum of catechins, and dimeric and trimeric procyanidins) were observed 
between the two vintages studied. The levels were higher in 2010 than in 2009 in all the studied stages (Fig. 1a and b). These higher levels in 2010 might be due either to higher initial levels in the grape or to higher extraction from skins and seeds. Alcohol content is one of the factors that can influence the extraction of these phenolic compounds, increasing it as the alcohol content raises. In fact, wines from 2010 vintage showed higher alcohol content (14.2-14.4\% according to the type of wine) than those of 2009 (13.5-14.1\%) which might have contributed to the higher levels of catechins and procyanidins of the former ones. Furthermore, differences in the evolution of the levels were also observed between vintages. The total content of catechins and procyanidins in the wines from 2010 was more stable than that of 2009. These differences between vintages were observed for all the types of wines (Control, Tannin and Overripe wines). This means that vintage has a stronger influence in the total content of catechins and procyanidins than the oenological practices evaluated in this study (adding oenological tannin or employing grapes at different stages of ripeness). Nevertheless, some common patterns can be observed for a same type of wine in both vintages. Taking into account the composition of the oenological tannin employed (42\% of catechins and procyanidins), it seems quite natural that the highest levels were observed in Tannin wines (Fig. 1a and b). Bautista-Ortín et al. (2007) also observed higher contents of monomeric, oligomeric and polymeric tannins in a tannin-treated wine $(40 \mathrm{~g} / \mathrm{hL})$ in relation to non-treated wines. However, whereas
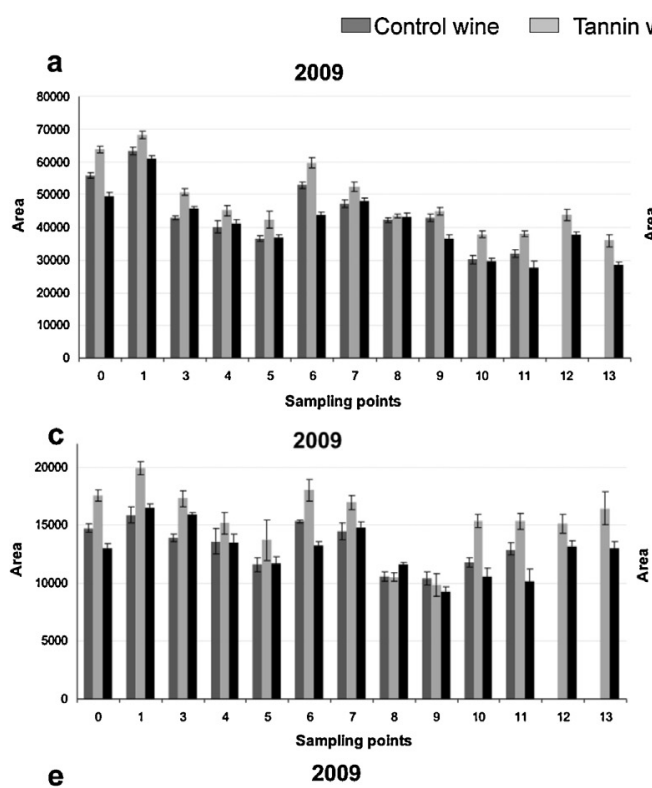

Overripe wine
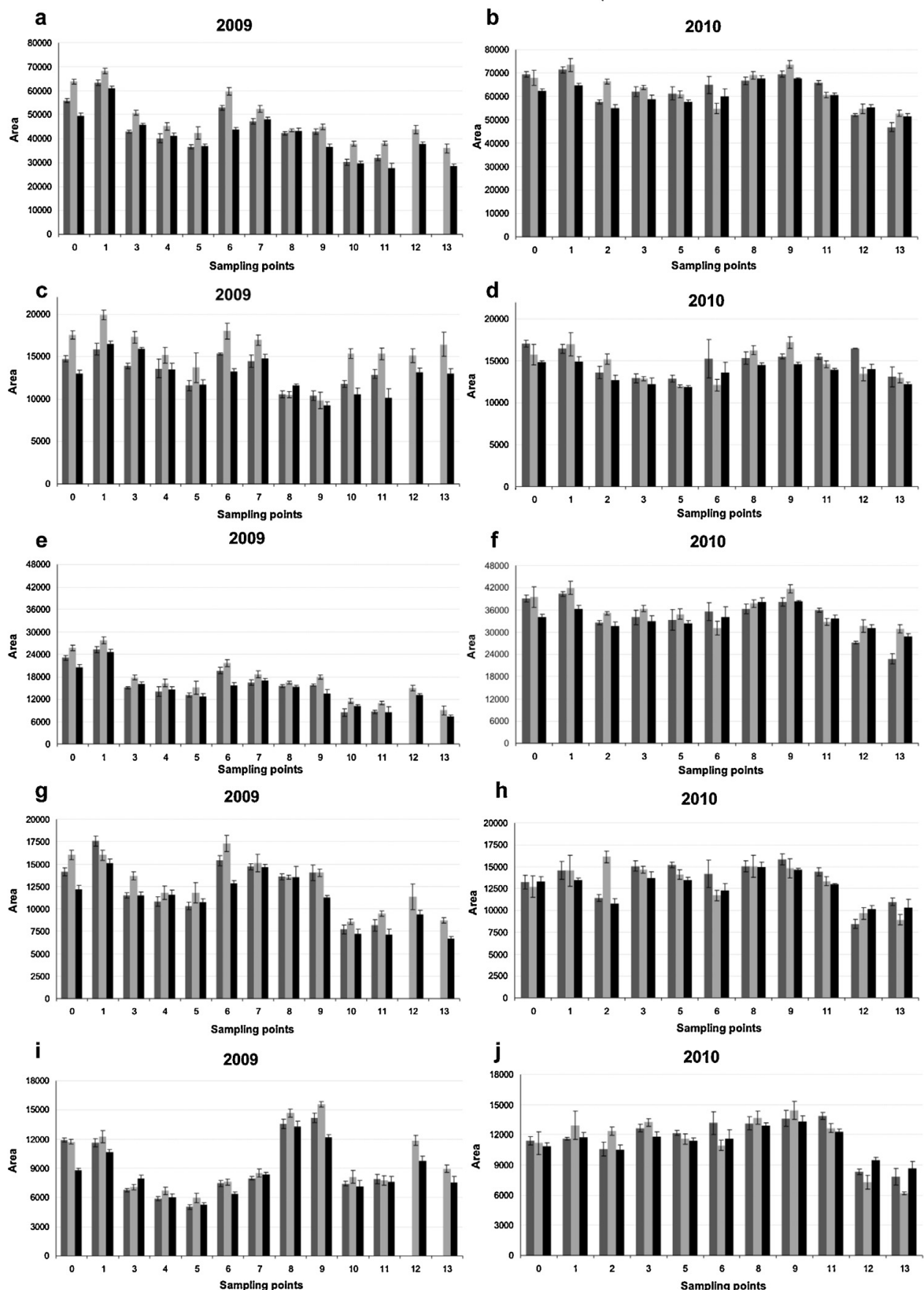

Fig. 1. Evolution of the mean levels $(n=3)$ of flavanols in Control, Tannin and Overripe wines in 2009 (left) and 2010 (right) vintages: Total catechins and procyanidins (a and $\mathrm{b})$, Sum of catechin and epicatechin (c and d), dimeric procyanidins (e and f), trimeric procyanidins ( $\mathrm{g}$ and $\mathrm{h}$ ) and total gallocatechin and prodelphinidins (i and j). 
the differences between Tannin and Control wines were relevant in 2009 , lower differences were found in some stages of 2010 where Control wines contained more catechins and procyanidins than Tannin wines. As will be discussed later, the addition of the oenological tannin might influence the levels of catechins and procyanidins in two different ways, i.e. directly, supplying catechins and procyanidins to the wine or indirectly, affecting the reactions in which these compounds are involved. Thus, differences between vintages might be related to differences in the indirect effect. Furthermore, the higher initial contents of catechins and procyanidins in 2010 vintage (Fig. 1a and b, Control wines) might also be responsible of the lower effect of oenological tannin on increasing the levels. Taking in consideration the studies of Parker et al. (2007), grapes of 2010 vintage might possess enough tannin to take part in polymerization, condensation or precipitation reactions and the additional tannin supplied by the oenological tannin did not produce an effect as noticeable as in 2009, where the initial contents were lower. In fact, Tannin wine from 2009 reached similar levels as Control wine from 2010 during the alcoholic fermentation/maceration process, thus compensating for the lower initial levels.

In relation to the maturity of the grapes, it can be seen that the total content of catechins and procyanidins was generally lower in Overripe wines than in Control wines, although in most cases differences were not significant. The contents of catechins and procyanidins in grape skin and seeds change differently with ripeness. In grape seeds they initially decrease and then stabilize (Ferrer-Gallego et al., 2010; Kennedy et al., 2000). On the contrary in grape skin they initially increase, reach a maximum and then show a slight decrease (Pérez-Magariño and González-San José, 2006).Thus, if grapes are too ripe, wines elaborated from them usually show lower levels of these compounds (Canals et al., 2005; PérezMagariño and González-San José, 2006). Furthermore, although there are discrepancies on the contents of procyanidins and on the mean degree of polymerization as grape ripens, Fournand et al. (2006) reported slight changes in the flavanol composition of grape skins during ripening (a decrease in the epigallocatechin units, an increase in the catechin and epicatechin-3-O-gallate and an increase in average polymer length). Taking into account that galloylation decreases extractability (Fournand et al., 2006; González-Manzano et al., 2006) and that tannin extractability seems to be mainly dependent on the size on the molecules (Fournand et al., 2006) it might be postulated that the lower procyanidin levels observed in Overripe wines might be also related to the changes in the proanthocyanidin composition during grape ripening.

In order to further evaluate the effect of the oenological practices in the levels of the catechins and procyanidins, monomers and dimeric and trimeric procyanidins were studied separately (Fig. 1c-h).

As in the case of the total content of catechins and procyanidins, some common patterns in the evolution of the levels of the monomers (catechin and epicatechin) can be observed in both vintages and in all the types of wine despite the relevant vintage effect (Fig. 1c and d). First, an increase in the levels can be observed from point 0 (density $1000 \mathrm{~g} / \mathrm{L}$ ) to point 1 (devatting), above all in 2009 vintage. This indicates that the extraction of these compounds from grape still takes place during the late fermentation/maceration process. After devatting, wine is separated from solid parts and no more extraction of these compounds can occur. Thus, from this point onwards the levels should decrease or at most stay stable. However, the levels of the monomers increased at different stages. The first racking of the wines (between points 5 and 6) caused an increase in the levels in all the wines and in both vintages. Nevertheless, subsequent rises observed during the ageing of the wine in the barrels or in the bottle were clearly dependent on vintage. All these rises can only be due to the release of these flavanol units from oligomeric or polymeric procyanidins. González-Manzano et al. (2006) reported that the mean degree of polymerization of the wines increases during winemaking and ageing which can only be attributed to rearrangements in the structure of procyanidins. As a result of these rearrangements monomers might be released from dimers or oligomers taking part in polymerization reactions. As observed in the total catechins and procyanidins, the effect of the addition of the oenological tannin was more noticeable when the initial levels were lower. Thus, Tannin wine of 2009 vintage reached the highest levels of monomers not only in the first stages but also during ageing. In the first stages it can be explained by the exogenous supply of catechins by the oenological tannin. Furthermore, oenological tannin seems to promote the release of monomers from oligomeric procyanidins, thus explaining the higher levels in Tannin wine in relation to Control wine during wine ageing. The effect of the addition of the oenological tannin in 2010 was not as noticeable as in 2009 and, in some stages, Control wine showed higher content of monomers than Tannin wine. Respecting Overripe wines, the levels of monomers were, in general, lower than in Control wine. Pérez-Magariño and González-San José (2006) also reported lower levels of catechins (determined by reaction with vanillin) in wines elaborated with grapes collected two weeks later than technological ripeness than those elaborated with grapes at technological ripeness. Nevertheless, wines elaborated with grapes collected only one week after technological ripeness showed the highest levels (Pérez-Magariño and González-San José, 2006). Although in the present study grapes employed to elaborate Overripe wines were collected in both vintages 13 days after technological ripeness, the effects in the levels of catechins and procyanidins and in those of other groups, as will be discussed later, are slightly different. Environment and climatic conditions may modify the delay between technological maturity ( $\mathrm{pH}$, soluble solids, acidity, etc.) and phenolic maturity (Ferrer-Gallego et al., 2011, 2012; Ribéreau-Gayon et al., 2000) and for the same degree of overripeness different phenolic maturities can be observed, thus explaining differences between vintages for the same grape variety and vineyard.

Unlike the levels of catechins that were similar in both vintages, those of the dimeric procyanidins were quite different (Fig. 1e and f). The initial levels in 2010 were almost 2-fold higher than those observed in 2009 highlighting again the influence of vintage in procyanidin composition of wine. For a given vintage, the evolution of the levels observed for monomers and dimeric procyanidins was very similar but the levels of dimeric procyanidins seemed to be more stable and less affected by winery practices such as racking. In 2009, the addition of the oenological tannin also produced an increase in the levels of dimeric procyanidins but relatively lower than in the case of monomers. In the first stages, it relates directly to the composition of the oenological tannin employed in this study that is richer in monomers than in dimers. During ageing, oenological tannin might promote the rearrangements of oligomeric procyanidins yielding, among others dimeric procyanidins. Nevertheless the formation of dimeric procyanidins might be partially reduced by the breakdown of the dimers themselves to originate monomers, which seems to be also promoted by the addition of the oenological tannin. Wines elaborated with the ripest grapes showed the lowest initial levels of dimeric procyanidins. However, levels tended to be similar during barrel ageing.

The behaviour observed for trimeric procyanidins (Fig. $1 \mathrm{~g}$ and h) was very similar to those observed for monomers and dimers. The direct effect of the addition of the oenological tannin in the levels of the trimers was less noticeable. It could be explained by a lower percentage of trimers than monomers and dimers in the composition of the oenological tannin employed. Respecting the 
indirect effect of the oenological tannin, in 2010 vintage trimers were more abundant in Control wine than in Tannin wine pointing to a higher breakdown of trimers promoted by the treatment. In relation to the degree of ripeness, the initial levels of trimers were generally higher in Control wines than in Overripe wines, but tended to be similar over time. From these results it seems that regarding the levels of catechins and procyanidins, the addition of the oenological tannin increases the total content of catechins and procyanidins above all by increasing the content of monomers either by direct supply or by promoting the release from oligomeric procyanidins. The use of grapes collected after technological maturity, on the other hand, leads to wines with lower contents in catechins and procyanidins either monomers, dimers or trimers. Nevertheless, as observed in previous studies (Pérez-Magariño and González-San José, 2006), shorter over-ripening periods may lead to wines richer in catechins and procyanidins. For this reason, it seems important to establish the delay between technological ripeness and harvesting date according to the desired type of wine.

\subsubsection{Gallocatechin and prodelphinidins}

Differences between vintages have also been observed in the evolution of the total content of gallocatechin and prodelphinidins. As in the case of catechins and procyanidins, levels changed more in 2009 than in 2010. However, the evolutions of procyanidins and prodelphinidins for a given vintage were different. In 2009, as shown in Fig. 1a, the highest values of catechins and procyanidins were reached during the first stages (during alcoholic fermentation/maceration) and then they tended to decrease. In the case of gallocatechin and prodelphinidins (Fig. 1i) the levels also showed a decrease after the initial increase but they began to increase during the stay of the wines in the barrels. In 2010, the levels of gallocatechin and prodelphinidins (Fig. 1j) tended to increase from the first stages until the stay in the bottle and then they decreased. In general Tannin wine showed the highest levels, but the effect of the oenological tannin was less noticeable than in the case of catechins and procyanidins. This is partly due to the composition of the oenological tannin, which was relatively richer in catechins and procyanidins than in gallocatechin and prodelphinidins, producing a lower direct effect. The use of grapes at different degrees of ripeness produced wines with similar levels of total prodelphinidins at most stages, although those elaborated with overripe grapes showed slightly lower content. This might be due to the lower initial content observed in Overripe wine which, in turn, might be due either to a lower content in the overripe grapes or to a higher difficulty in the extraction of these compounds in these grapes than in the grapes harvested at technological ripeness. In fact, during grape ripening flavanols tend to increase up to a maximum and then they decrease (Ribéreau-Gayon et al., 2000). Thus, it is possible that prodelphinidin content in the grapes employed to elaborate Overripe wines had already reached the maximum and had begun the decreasing phase. Furthermore, as can be seen in Fig. $1 \mathrm{i}$ and $\mathrm{j}$ the highest levels of gallocatechin and prodelphinidins in Control wines in both vintages were already reached before the end of alcoholic fermentation (point 0 ) whereas in the case of Overripe wines, they were reached at the end of alcoholic fermentation (point 1). This is indicative of a slower and more difficult extraction of prodelphinidins when grapes are more mature despite the higher alcohol content of the wine made from them. This is in agreement with previous studies which reported that higher contents of sugars in grape skins are related to a higher skin thickness making more difficult the extraction of phenolic compounds (Río Segade et al., 2010; Torchio et al., 2010). The lower extraction of gallocatechin and prodelphinidins might be also related to the changes in the composition of cell-wall during ripening (Ortega-Regules et al., 2006) and to the possible association of these phenolic compounds to cell-wall components (Fournand et al., 2006).

An interesting difference that can be observed in the behaviour of catechins and procyanidins towards gallocatechin and prodelphinidins in Control wines (made from grapes harvested at technological ripeness) is that the former ones reach the highest levels at the end of alcoholic fermentation whereas the latter ones reach them earlier. This can be explained by the fact that the extraction of catechins and procyanidins (coming from seeds and grape skins) is promoted by higher alcoholic contents and longer maceration times than those required by prodelphinidins (only present in skins) (González-Manzano et al., 2004; Ribéreau-Gayon et al., 2000). In some regions, wines are devatted at density $1000 \mathrm{~g} /$ $\mathrm{L}$ (point 0 ). If this oenological practice is carried out in wines elaborated with grapes collected at technological maturity, there would only be differences in the catechin and procyanidin content between the wine devatted at point 0 and that devatted at point 1 , the former possessing lower contents. On the contrary, if this practice is performed in wines elaborated with overripe grapes, both the catechins and procyanidin content and the gallocatechin and prodelphinidin content would be lessened in relation to wine devatted at point 1 . These factors should be taken into account in order to elaborate a wine richer or poorer in procyanidins and/or in prodelphinidins. This could be of interest as these compounds might be differently involved in mouthfeel perception (astringency, bitterness, etc.) (Ferrer-Gallego et al., 2010, 2012), since catechins and gallocatechins have shown different ability to precipitate the salivary proteins (Bacon and Rhodes, 1998).

\subsection{Gallic acid}

Fig. 2a and $\mathrm{b}$ shows the evolution of the levels of gallic acid during winemaking and ageing. Gallic acid content increased from alcoholic fermentation to barrel ageing in all cases. Since grape seed are the main source of gallic acid in wines, the increase over time observed after devatting (point 1) might be due to the breakdown of galloylated procyanidins and to hydrolyses of glycoside combinations of gallic acid (Ribéreau-Gayon et al., 2000). Furthermore, since the wines monitored in the present study stay

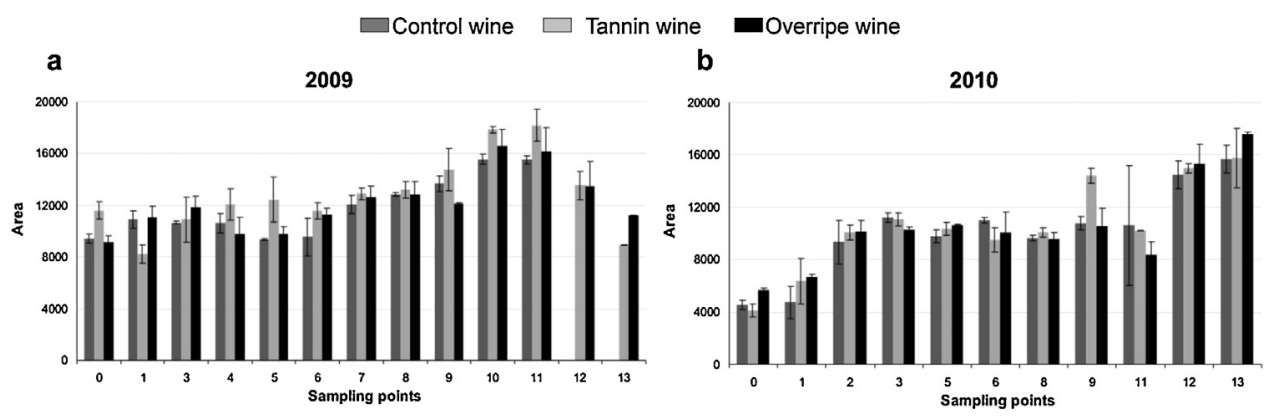

Fig. 2. Evolution of the mean levels $(n=3)$ of gallic acid in Control, Tannin and Overripe wines in 2009 (a) and 2010 (b) vintages. 
in oak barrels for long time periods (from malolactic fermentation to bottling) gallic acid can be released from its galloylated precursors that are extracted from oak barrels to wine (Ginjom et al., 2011). In 2010 an important increase in the levels of gallic acid was observed during malolactic fermentation as previously reported (Cabrita et al., 2008; Martínez-Pinilla et al., 2012) and then, they remained relatively stable during barrel ageing and until bottling. On the contrary, in 2009 levels were barely affected by malolactic fermentation and they increased from the first racking and during all the barrel ageing. As will be discussed later, similar behaviours were observed in the case of caffeic and $p$-coumaric acids for each vintage. Furthermore, differences in the evolution of the levels of gallic acid during bottle ageing were observed between vintages: whereas in 2009 the content decreased, in 2010 it increased.

Wines elaborated with overripe grapes showed in most stages and in both vintages higher contents than Control wines. However, the effect of the addition of the oenological tannin was different between vintages. In 2009, Tannin wine showed the highest content in almost all the steps of winemaking and ageing in the barrel which can be explained, as in the case of proanthocyanidins, by the direct supply of this compound from the oenological tannin added and probably by its indirect effect, through the increase of hydrolysis reactions leading to a release of gallic acid units. Bautista-Ortín et al. (2007) also detected higher contents of gallic acid in a wine treated with an oenological condensed tannin than in the non-treated one. In 2010, on the contrary, Tannin wine only showed higher levels than Control wine in very few stages and a general behaviour for this type of wine cannot be reported. Thus, the effect of the addition of oenological tannin on the evolution of gallic acid has been shown to be clearly dependent on vintage.

\subsection{Hydroxycinnamic acids and their tartaric esters}

In grapes hydroxycinnamic acids are usually esterified with tartaric acid. During winemaking they can be released from their tartaric esters. Thus, free and esterified forms can be detected in wines. Hydroxycinnamic acids can be in turn transformed into volatile phenols which are responsible for certain olfactory defects of wines or can take part in reactions with anthocyanins leading to colour modifications (Quijada-Morín et al., 2010). For these reasons it is important to know the effects of the oenological treatments on their levels.
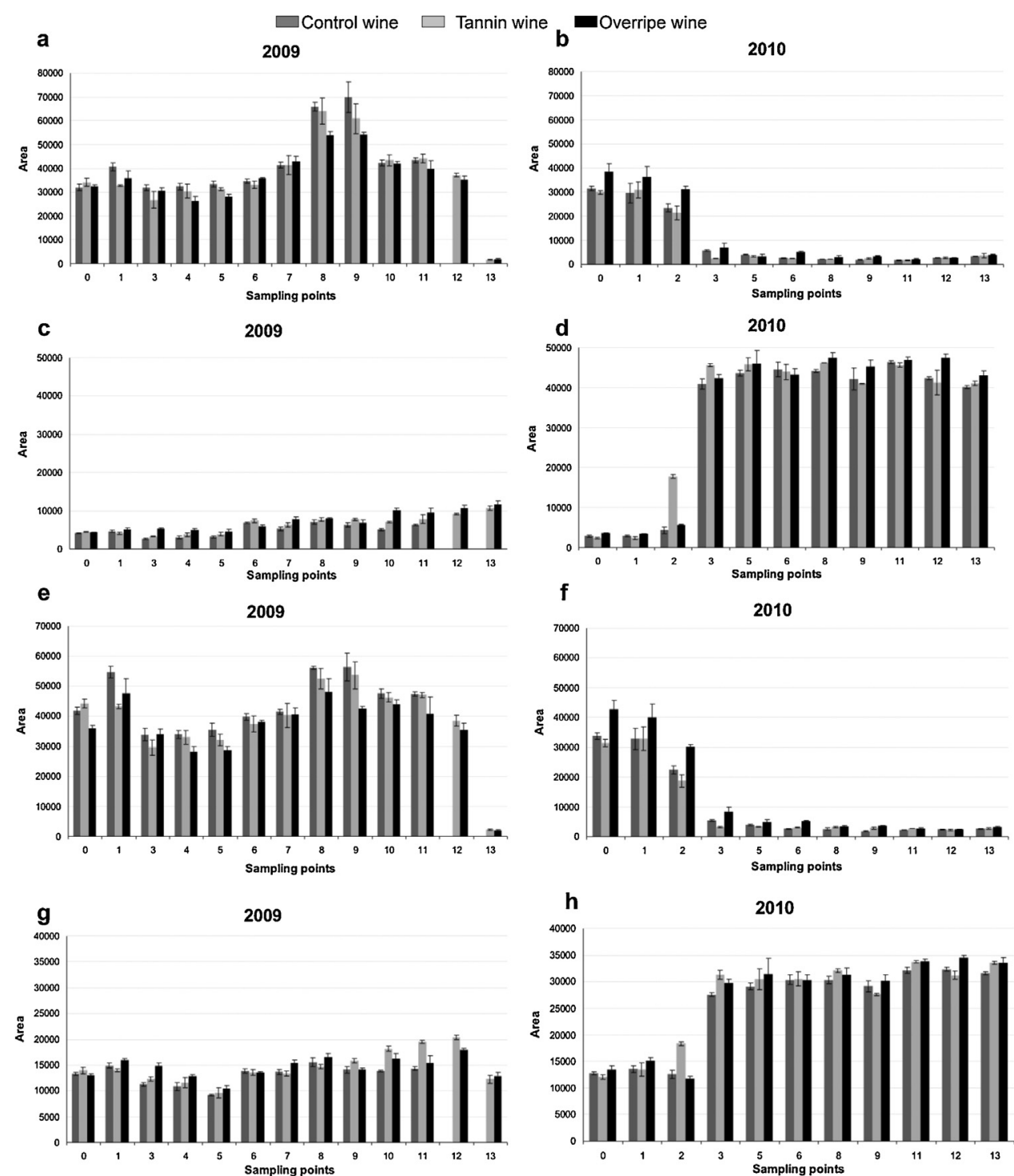

Fig. 3. Evolution of the mean levels ( $n=3$ ) of caftaric (a and b), caffeic (c and d), coutaric (e and f) and $p$-coumaric ( $g$ and h) acids in Control, Tannin and Overripe wines in 2009 (left) and 2010 (right) vintages. 
As can be seen in Fig. 3, these compounds also show an important vintage effect. As expected, an inverse relationship between the levels of the tartaric esters (caftaric and coutaric acids, Fig. 3a, b, e and f) and those of their corresponding hydroxycinnamic acids (caffeic and $p$-coumaric acids, Fig. $3 c, d, g$ and $h$ ) has been observed. Despite vintage effect, the same behaviours within the same vintage have been observed for each ester/free acid pair (caftaric/caffeic acid and coutaric/p-coumaric acid). Initial levels of caftaric and coutaric acids were quite similar within the same vintage and slightly higher in 2009 vintage in relation to 2010. Nevertheless, the evolution was quite different in both vintages. In 2010, the highest levels were reached during alcoholic fermentation and from then onwards they decreased. The highest decrease took place during malolactic fermentation and from this moment the levels remained more or less stable but quite low in relation to initial levels. The free hydroxycinnamic acids, on the contrary, slowly increased their levels during alcoholic fermentation and showed an important increase during malolactic fermentation. Finally, the levels remained more or less stable during ageing in the barrel and in the bottle. As indicated previously, this behaviour was also observed for gallic acid in 2010 , although the increase in the levels during malolactic fermentation in the case of gallic acid was relatively lower. The influence of malolactic fermentation on the content of free hydroxycinnamic acids has already been observed in previous studies (Cabrita et al., 2008). The release of the hydroxycinnamic acids from their esters has been attributed to lactic acid bacteria which can use the tartaric esters as substrates due to their cinnamoyl esterase activity (Hernández et al., 2007). On the contrary, in 2009, the release of the hydroxycinnamic acids from their esters did not seem to be promoted and the levels of both types of compounds remained quite stable. This behaviour has also been previously reported not only in Tempranillo variety but also in some Spanish minority varieties (Martínez-Pinilla et al., 2012). In that study, it was not possible to quantify the free hydroxycinnamic acids since they were below the limit of quantification. In our study the levels of free acids in 2009 were much lower than those of 2010 vintage but were clearly detectable and quantifiable. Thus, the behaviour of the hydroxycinnamic acid and their tartaric esters seems to be dependent on vintage. However, some effects of the oenological treatments have been observed in both vintages.

First, the oenological tannin did not supply hydroxycinnamic acids or their tartaric esters to the wines to which it was added. In fact, initial levels of these compounds have been higher in Control wines than in Tannin wines. Nevertheless, it seems that the addition of this oenological tannin might promote the release of the hydroxycinnamic acids from their corresponding tartaric esters. The increase in the levels of caffeic and $p$-coumaric acids observed in 2010 during malolactic fermentation was higher and took place earlier (point 2 instead of 3 ) in Tannin wine than in Control wine. Nevertheless, with ageing, levels tended to be similar in both types of wine.

Second, although there is an important vintage effect in the results of employing overripe grapes on the levels of the tartaric esters (in 2009, levels in Control wine were higher than those in Overripe wine but in 2010 levels were higher in Overripe wine) wines elaborated with riper grapes showed, above all at the end of the study in both vintages, higher contents of free hydroxycinnamic acids than Control wines. Thus, independently of the effect on tartaric esters, the use of overripe grapes leads to a wine richer in hydroxycinnamic acids. Furthermore, these higher levels are maintained over ageing. This is a difference between the effects of one or other oenological practice. Adding oenological tannin seems to promote the increase but during a limited range of time and the effect of employing overripe grapes is noticeable during the winemaking and ageing.

\subsection{Anthocyanins and anthocyanin-derived pigments}

\subsubsection{Anthocyanin 3-O-glucosides}

Fig. $4 \mathrm{a}$ and $\mathrm{b}$ shows the evolution of this group of compounds in both vintages. Unlike proanthocyanidins, anthocyanins did not show a strong vintage effect and the evolution was very similar in both vintages. Nevertheless, differences in the contents were observed between vintages, those of the wines of 2010 being higher than those of 2009. These higher contents might be due either to higher initial contents or to higher extraction from grapes. In fact, the initial anthocyanin contents in grapes (measured as the absorbance at $520 \mathrm{~nm}$ ) were higher in 2010 than in 2009 (data not shown). Furthermore, as indicated in the case of proanthocyanidins, the higher alcohol content of the wines of 2010 in relation to the wines of 2009 might have contributed to the higher extraction from grapes, although the extraction of the anthocyanins is less dependent on the alcohol content than proanthocyanidins.

Anthocyanin content increased for most of the wines from point 0 (density $1000 \mathrm{~g} / \mathrm{L}$ ) to point 1 (devatting) as expected, since grape skins are still in contact with must/wine until devatting and extraction of pigments is, therefore, possible. From the results obtained in both vintages it seems that the addition of the oenological tannin promotes the extraction of anthocyanins from grapes to must and increases the rate of extraction. In fact, in points 0 and 1, where extraction is still possible, Tannin wines always showed the highest levels of anthocyanins. Furthermore, the highest levels were reached earlier in Tannin wines (point 0 in 2010 vintage) than in Control and Overripe wines. This greater and faster extraction of the anthocyanins in Tannin wines can be explained by the presence in the oenological tannin of some compounds that may promote the extraction through copigmentation reactions such as flavanols and phenolic acids (Boulton, 2001; Darias-Martín et al., 2001; González-Manzano et al., 2009). Respecting anthocyanin extraction and ripeness state of the grapes, different results have been observed between vintages. In 2009, the wine elaborated with grapes collected at technological maturity (Control wine) reached higher levels than that elaborated with overripe grapes, whereas in 2010 the opposite pattern was observed in most stages. These differences in the behaviour can be attributed to the delay between technological and phenolic ripeness that may change among vintages. Anthocyanins accumulate during all the ripening process and ideally they reach a maximum at full technological maturity. From this point onwards, their content decrease (Fournand et al., 2006; Hernández-Hierro et al., 2012; Río Segade et al., 2008). Depending on the vintage the maximum of the anthocyanin accumulation may coincide with technological maturity but may also occur earlier, later or not occur (Ribéreau-Gayon et al., 2000). Thus, although grapes employed in the elaboration of the wines studied in the present work were collected in both vintages at the same "ripe" and "overripe" moments from a technological point of view, it can be seen that their phenolic ripeness were not the same. Nevertheless, anthocyanin content in grapes is not the only factor conditioning the levels in wine. Extractability of these anthocyanins from grapes to must is as relevant as content and it has been observed that it increases in overripe grapes in relation to mature grapes (Hernández-Hierro et al., 2012) probably due to the changes in the composition of cellular wall during ripening (Bautista-Ortín et al., 2007; Ortega-Regules et al., 2006; Ribéreau-Gayon et al., 2000). This would explain why in 2010 both Control and Overripe wines reached the same anthocyanin levels at devatting despite the difference in the levels at point 0 . The content in mature and overripe grapes in 2010 might be similar initially, but the higher extractability in overripe grapes would have caused the maximum levels to be reached earlier in Overripe wine than in Control wine. On the contrary, in 2009 Overripe wine never reached the levels 

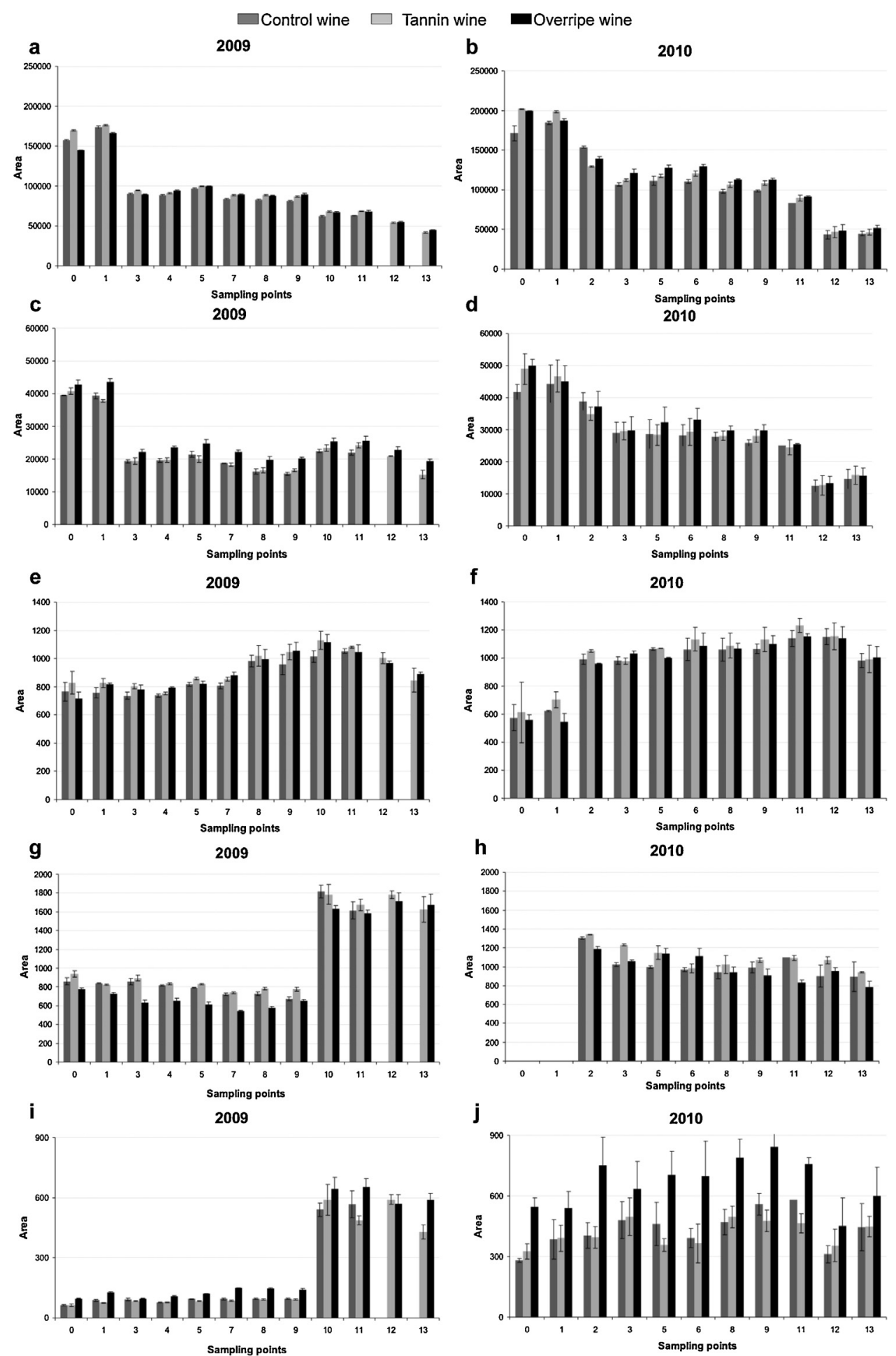

Fig. 4. Evolution of the mean levels $(n=3)$ of anthocyanins and derivative pigments in Control, Tannin and Overripe wines in 2009 (left) and 2010 (right) vintages: anthocyanin 3-O-glucosides ( $\mathrm{a}$ and b), anthocyanin 3-O-acylglucosides (c and d), Flavanol-anthocyanin direct condensation products (e and f), A-type vitisin of Malvidin 3-Oglucoside ( $\mathrm{g}$ and $\mathrm{h}$ ) and Vinylphenol-Malvidin 3-O-glucoside pyranoanthocyanin ( $\mathrm{i}$ and $\mathrm{j}$ ).

reached in Control wine despite the theoretical higher extractability. This would mean that at technological over-ripeness, the anthocyanin content of the grapes of 2009 vintage was in the decreasing phase whereas in 2010 it was still in the plateau phase. Thus, employing overripe grapes would be interesting if the anthocyanin content is still high or has just begun the decreasing phase.

During malolactic fermentation a noteworthy decrease (from point 1 to point 3 ) in the levels of the anthocyanins is observed for all the wines and in both vintages. Martínez-Pinilla et al. (2012) have also observed a decrease of around 30\% in the levels of anthocyanins during malolactic fermentation. This decrease can be attributed either to the reaction of anthocyanins leading to derivative pigments or to the degradation, oxidation or polymerization reaction taking place at this stage. At the end of malolactic fermentation (point 3), Tannin and Overripe wines showed higher levels than Control wines, indicating a higher protection of the anthocyanins in the treated wines. Nevertheless, as can be 
seen in 2010, during malolactic fermentation (point 2) Control wines possessed the highest levels. This can be attributed to a higher reactivity and higher formation of anthocyanin derivatives during this stage in the treated wines. In fact as would be discussed later, the levels of some pyranoanthocyanins and some flavanol-anthocyanin condensation products are higher in the treated wines than in Control wines during this stage. Thus, adding oenological tannin or employing overripe grapes increases the synthesis of some anthocyanin derivatives and, at the same time, protects anthocyanins.

During barrel ageing levels remained quite stable until the first racking, which took place between point 5 and 6 , and slowly decreased from then onwards (from point 6 to 11). Unlike in the case of proanthocyanins, rackings do not seem to affect anthocyanin levels. During the stay in the barrel, reactions leading to anthocyanin derivatives still take place as well as degradation reactions, both being responsible of the decrease observed in the levels, which was much lower than that occurring during malolactic fermentation. Differences among wines were the same as those observed after malolactic fermentation and treated wines showed higher levels than Control wines. In 2010, Overripe wine showed higher levels than Tannin wine. This might be due either to a better protection of anthocyanins or to a lower formation of anthocyanin derivatives.

The differences in the levels observed for the three types of wines during barrel ageing were also present during bottle ageing. Whereas in 2010 levels remained quite stable during bottle ageing, they decreased during the same period in 2009.

Bautista-Ortín et al. $(2006,2007)$ reported similar results about the use of overripe grapes (Bautista-Ortín et al., 2006) or oenological tannin (Bautista-Ortín et al., 2007), observing higher extractability for anthocyanins after reaching their maximum content in grapes or higher anthocyanin contents in tannin-treated wines in relation to non-treated ones even during ageing period. Nevertheless, they indicate that the effect of these oenological practices depend on the characteristics of the grapes at the moment of harvest which in turn may change from one vintage to another.

\subsubsection{Anthocyanin 3-O-acylglucosides}

Fig. $4 \mathrm{c}$ and $\mathrm{d}$ shows the evolution of the acylated anthocyanins levels in both vintages. As can be seen, it is very similar to that observed for the non-acylated anthocyanins (Fig. 4a and b) and the differences among wines can, therefore, be explained as in the case of the non-acylated anthocyanins. However, whereas in 2010 the behaviour is almost identical to non-acylated anthocyanins, in 2009 there are some differences. First, Overripe wine showed the highest initial levels and, as a consequence, the highest levels during all the studied period. This was not the case for nonacylated anthocyanins in Overripe wine, which showed the lowest initial levels. This fact might be interpreted either as a higher relative extractability of acylated anthocyanins in overripe grapes or as a higher content of acylated anthocyanins in overripe grapes in relation to mature grapes. Nevertheless, according to previous studies (Fournand et al., 2006; Hernández-Hierro et al., 2012), although anthocyanins extractability increases throughout grape ripeness, the relative extractability is higher for non-acylated anthocyanins than for acylated. Among acylated anthocyanins, coumaroylglucoside derivatives have been shown to be much less extractable than the other acylglucoside derivatives (Fournand et al., 2006). Furthermore, the content of anthocyanins decrease as grapes become overripe. However, the maximum levels of nonacylated anthocyanin glucosides, acetylglucoside derivatives and coumaroylglucoside derivatives are reached at different sugar contents in the pulp (Fournand et al., 2006), the latter ones being reached at higher sugar contents. Thus, one possible explanation for the higher levels of acylated anthocyanins in Overripe wine in 2009 is that the moment of technological over-ripeness, in that vintage, might coincide with the maximum levels of coumaroylglucoside derivatives in grapes whereas non acylated anthocyanins were in decreasing phase as previously indicated. Second, in 2009 during barrel ageing between the second and third racking (from point 9 to 10) an increase in the levels was observed for all the types of wines. This is not the first time that this increase in the levels has been observed during barrel ageing. As previously reported (Alcalde-Eon et al., 2006) this might be due to the acylation of anthocyanins with hydroxycinnamic acids present in the wine. The different behaviour of the hydroxycinnamic acids and their tartaric esters in the different vintages may be responsible for the differences respecting the acylation of anthocyanins during barrel ageing. In fact, as will be reported later, an important increase in the levels of the vinylphenolmalvidin 3-O-glucoside-pyranoanthocyanin whose synthesis is dependent on a hydroxycinnamic acid ( $p$-coumaric acid) also occurred during this same period of time.

\subsubsection{Anthocyanin-derived pigments}

Although from a quantitative point of view, anthocyanin 3-Oglucosides are the major group of pigments in grapes and wine, other minority groups have to be also considered since they contribute to the overall colour of wine. Among these minority groups, flavanol-anthocyanin direct condensation products and different kinds of pyranoanthocyanins have been considered in this study.

3.4.3.1. Flavanol-anthocyanin direct condensation products. As can be seen in Fig. $4 \mathrm{e}$ and $\mathrm{f}$ the levels of these anthocyanin derivatives were higher in 2010 than in 2009 for all the types of wines. This is a consequence of the higher levels of anthocyanins and proanthocyanidins observed in 2010 in relation to 2009, which are the precursors of this kind of pigments. Respecting the evolution of the flavanol-anthocyanin direct condensation products there are similarities and differences between both vintages. In both cases, the levels tended to increase over time. However, a decrease is observed in the last stages, occurring earlier in 2009 (from the third racking) than in 2010 (during bottle ageing). This behaviour is related to the evolution of proanthocyanidins which tended to decrease earlier and more in 2009 than in 2010. In both vintages, it has been observed that rackings increased the levels of these anthocyanin derivatives. This increase might be related to the oxygenation of the wine and to the changes in the relationship between wine and wood that take place during racking. Oxygen and some of the compounds extracted from wood, as the ellagitannins, seem to promote the condensation reaction between proanthocyanidins in wine (Vivas and Glories, 1996) and are expected to also promote condensation reactions between anthocyanins and proanthocyanidins (Alcalde-Eon et al., 2006).

Regarding the oenological treatment, Tannin wines were expected to show the highest content of these anthocyanin derivatives since the oenological tannin employed in this study not only supplied proanthocyanins to the wine but also ellagitannins. This was more noticeable in 2010 than in 2009 and it is in accordance with the lower increase in the levels of oligomeric procyanidins observed in 2010 in relation to 2009 in Tannin Wines: a higher relative amount of these oligomeric procyanidins is taking part in condensation reactions. On the other hand, whereas in 2010 the content in Tannin wine was slightly higher than in Overripe wine, in 2009 the effect of employing overripe was similar to that of adding oenological tannin, despite the differences in the anthocyanin/proanthocyanidin ratio, reaching in both cases higher levels than in Control wines. 
3.4.3.2. A-type vitisin of malvidin 3-O-glucoside (Vitisin A). The evolution of the levels of this compound in both vintages is shown in Fig. $4 \mathrm{~g}$ and $\mathrm{h}$. There are important differences between vintages. The first one is the moment at which this compound is first detected in wines. In 2009 it is detected from the first sampling point (density $1000 \mathrm{~g} / \mathrm{L}$ ) in all the types of wines whereas in 2010 it is first detected during malolactic fermentation (sampling point 2). In both vintages, once this compound is first detected its content tends to decrease over time, until the second racking (between points 8 and 9) where again differences between vintages can be observed. Vitisin A increased in most of the wines of both vintages, but the magnitude of the increase was very different. Results observed for wines of the 2010 vintage were more in accordance than those of 2009 with those obtained in our laboratory in similar wine samples (Alcalde-Eon et al., 2006). The synthesis of A-type vitisins requires not only the presence of anthocyanins and pyruvic acid but also the presence of oxidants to complete the last step of the synthesis (Asenstorfer et al., 2003). Although oxygen is not the oxidant directly involved in this reaction, it can be converted into reactive oxygen species, conversion that is promoted by some wine components such as ellagitannins, which are released from wood. During fermentation steps, oxygen is less available for oxidation reactions since it is employed by yeasts for their multiplication. Furthermore, during malolactic fermentation lactic bacteria can use part of the pyruvic acid synthesized by yeast (Asenstorfer et al., 2003). Thus, the optimal conditions for the synthesis of A-type vitisins are not reached until the end of alcoholic fermentation and in some cases during malolactic fermentation, which, in the present study, was carried out in oak-wooden barrels.

Despite these differences in the evolution of the levels between vintages, some similar results have been obtained in relation to the different oenological practices employed. Tannin wines showed in most of the sampling points the highest contents of Vitisin A which can be related to the supply, by the oenological tannin, of ellagitannins and other compounds that can promote the formation of reactive oxygen species. On the contrary, the lowest levels of Vitisin A were observed in Overripe wines in most of the sampling points. The expression of enzymes involved in pyruvate metabolism, which can promote the transformation of this compound into ethanol or acetaldehyde, is generally promoted during grape ripening (Sweetman et al., 2009). Thus, grape ripeness might be related to a higher transformation of pyruvic acid in wines elaborated with these grapes and consequently with a lower formation of A-type vitisin.

3.4.3.3. Vinylphenol-malvidin 3-O-glucoside pyranoanthocyanin. Differences in the behaviour of this compound between vintages can also be observed (Fig. $4 \mathrm{i}$ and j). It has been demonstrated that this kind of pyranoanthocyanins can be synthesized by two different mechanisms: a fast reaction between the anthocyanin and the vinylphenol originated in the wine by decarboxylation of p-coumaric acid by yeasts (Fulcrand et al., 1996) and a slower reaction between the anthocyanin and the intact hydroxycinnamic acid (Schwarz et al., 2003). Thus, independently of the mechanism involved, $p$-coumaric acid is necessary for the synthesis of this kind of pyranoanthocyanins. The first type of reaction is conditioned by yeast activity and is important during the first stages of winemaking. The second can occur during all the ageing period provided that the hydroxycinnamic acid is available. As previously reported for hydroxycinnamic acids and their tartaric esters, important differences in the evolutions between vintages have been observed. The higher levels of free $p$-coumaric acid and the earlier release from tartaric esters in 2010 in relation to 2009 can easily explain the higher content of this pyranoanthocyanin and from earlier stages in the wines from 2010 vintage. Furthermore, the increase in the levels observed in 2009 from point 10 (before the third racking) occurs simultaneously to the increase observed in the levels of acylated anthocyanins, indicating a higher availability of hydroxycinnamic acids during this period in all the wines of the 2009 vintage. Regarding the effects of the different oenological treatments, Overripe wines showed the highest levels of this pyranoanthocyanin, which is in accordance with the results obtained for hydroxycinnamic acids and more precisely with the higher levels of $p$-coumaric acid in Overripe wines in relation to the other types of wines. Nevertheless, differences in the levels of hydroxycinnamic acids among wines are not great enough to explain the highest synthesis of the vinylphenol derivative in the wine elaborated with overripe grapes. There has to be another factor(s) in Overripe wines promoting the synthesis of this kind of pyranoanthocyanin. In the case of Tannin wines, no significant differences were observed in the levels of the vinylphenol derivative of malvidin 3-O-glucoside in relation to those of Control wines. Thus, it seems that the addition of oenological tannins to wine do not affect the synthesis of vinylphenol derivatives.

\subsection{Evolution of the CIELAB colour parameters}

The evolution of the CIELAB parameters, Lightness $\left(L^{*}\right)$, Chroma $\left(C_{\mathrm{ab}}^{*}\right)$ and hue $\left(h_{\mathrm{ab}}\right)$ has been studied for all the samples and in both vintages. These parameters have been calculated from the visible spectrometric measurements of the samples adjusted at $\mathrm{pH} 3.6$ and using CromaLab ${ }^{\circledR}$ software.

\subsubsection{Lightness $\left(\mathrm{L}^{*}\right)$}

Lightness tended to increase during all the studied period (Fig. 5a and b). This was in agreement with previous studies (García-Puente Rivas et al., 2006; Pérez-Magariño and GonzálezSan José, 2006). Wines from 2009 vintage were more stable, in relation to lightness, than wines from 2010 vintage and although at the end of the study all the wines showed similar values, the wines of 2010 vintage were initially darker than those of 2009. Those initial lower values can be related to the higher levels of anthocyanins and proanthocyanidins in the 2010 wines. Control wines showed the highest Lightness values and no clear differences were observed between the treated wines. The higher values for Control wines in relation to the treated wines can be related to fact of possessing the lowest anthocyanin content. Pérez-Magariño and González-San José (2006) also reported lower Lightness values for wines made from grapes harvested one week after technological ripeness. Nevertheless, they also observed that an excessive overripening may lead to $L^{*}$ values similar to those of the wines elaborated with grapes harvested at technological ripeness.

\subsubsection{Chroma $\left(C_{\mathrm{ab}}^{*}\right)$}

Regarding Chroma, wines from 2010 showed the highest initial values (Fig. 5c and d) which might be interpreted as wines with colour more different from grey than those of 2009. This might be due to the higher initial content of anthocyanins in the wines from 2010 in relation to those of 2009. As reported in previous studies (García-Puente Rivas et al., 2006; Pérez-Magariño and GonzálezSan José, 2006) Chroma tended to decrease over time. This decrease was more noticeable in 2010 vintage which might be attributed to the relatively higher decrease in the initial content of anthocyanins. In relation to the oenological treatment there is not a reproducible behaviour for a same type of wine in both vintages. In general, Overripe wine showed the lowest initial values, but as wine aged, it reached similar values to the other two wines and at the late stages it even show higher chroma than the others. In these stages Overripe wine also showed the highest levels of anthocyanins. Pérez-Magariño and González-San José (2006) also reported lower chroma values in wines made from overripe grapes in early winemaking steps. However, in aged wines they reported that the 

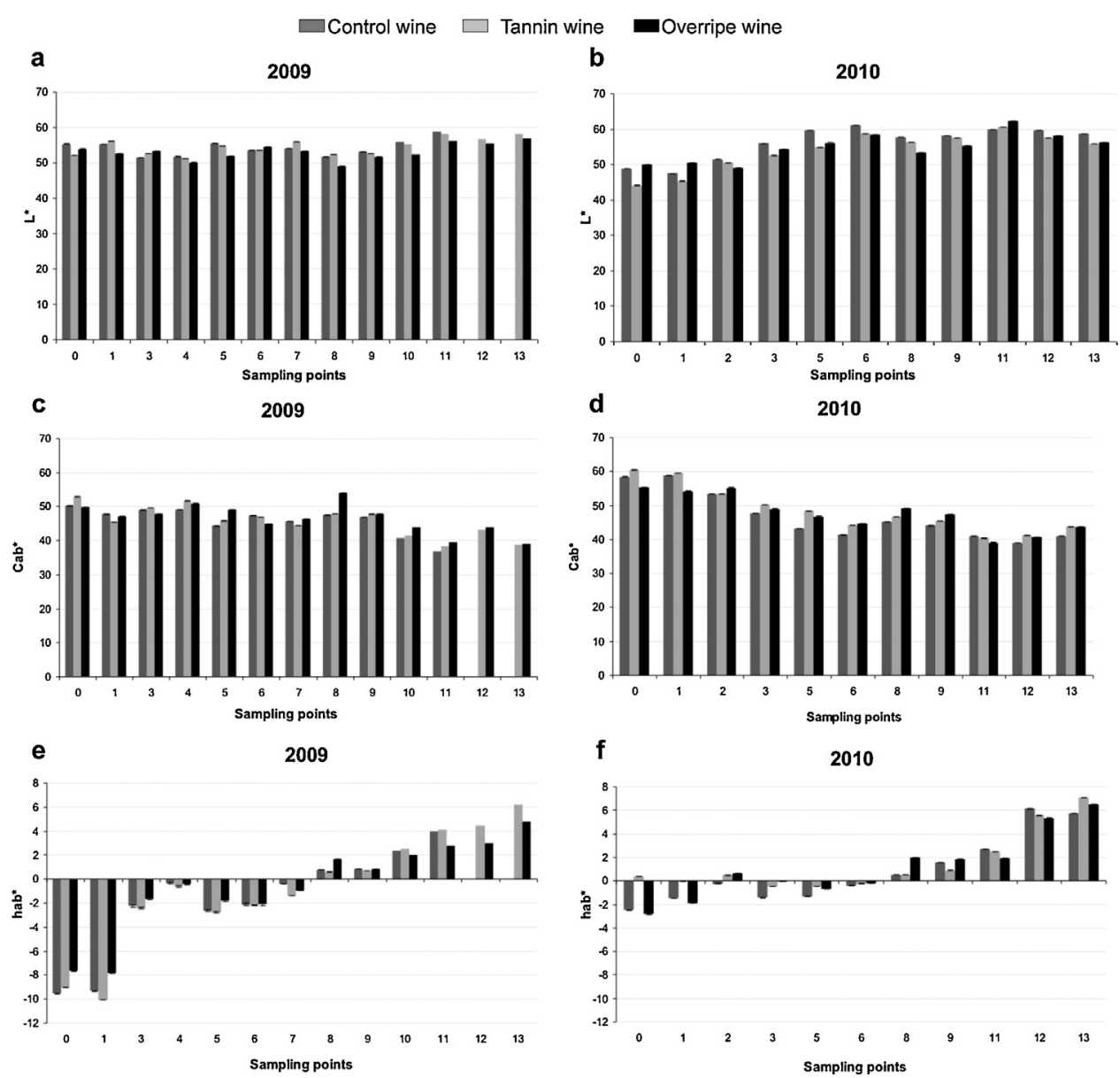

Fig. 5. Evolution of the CIELAB parameters $(n=3)$, Lightness $\left(L^{*}\right)$ (a and b), Chroma $\left(C_{\mathrm{ab}}^{*}\right)\left(\mathrm{c}\right.$ and d) and hue $\left(h_{\mathrm{ab}}\right)$ (e and f), in Control, Tannin and Overripe wines in 2009 (left) and 2010 (right) vintages.

behaviour was dependent on grape variety. Tannin wine showed initially the highest chroma value along with the lowest Lightness value which might be related to the higher anthocyanin extraction. From these results, it seems that chroma co-relates well with anthocyanin content, as observed previously (García-Puente Rivas et al., 2006).

\subsubsection{Hue $\left(\mathrm{h}_{a b}\right)$}

As can be seen in Fig. 5e and $\mathrm{f}$, hue evolved in both vintages from blue to red/orange which is in agreement with the general observation that wine colour changes from bluish red to brick red during wine ageing also reported in previous studies (GarcíaPuente Rivas et al., 2006). Nevertheless, the range of variation was different for each vintage (circa 16 points in 2009 from stage 0 to stage 13 and circa 8 points in 2010). The values reached after 6 months of bottle ageing were slightly higher in 2010, but it was in the initial sampling points where wines from 2009 differed from those of 2010. Wines from 2009 were initially more bluish than those of 2010. An important vintage effect was observed when analysing the differences due to the oenological treatments and only one difference among treatments was observed in both vintages. During bottle ageing Tannin wines showed higher values of hue than Overripe wines, but differences were probably not great enough to be detected.

Thus, in relation to CIELAB colour parameters, only a clear relationship between Lightness and the oenological treatments here evaluated can be established. Both treatments produced wines darker than Control ones. As in our study, Pérez-Magariño and González-San José (2006) reported that wines elaborated with grapes harvested one or two weeks after oenological maturity were darker in the initial stages and/or remained darker after 18 months of ageing than wines elaborated with grapes collected at technological maturity. These authors also reported that wines elaborated with grapes collected one week after technological maturity showed the highest increase in \%blue over time. Nevertheless, in our study, no clear effects of the treatments either on chroma or on hue were observed. Respecting the effect of the addition of oenological tannin on the colour of the wines to which it is added, Parker et al. (2007) reported minor differences in CIELAB parameters between treated and non-treated wines and no statically significant differences between the treatments for wine colour density.

In order to evaluate if the modifications in the colour parameters caused by the different oenological treatments are high enough to allow the discrimination between two samples by the human eye, colour differences $\left(\Delta E_{\mathrm{ab}}^{*}\right)$ were calculated. Table 2 shows colour differences between Control and each treated wine and between Tannin and Overripe wines in both vintages and at three different moments of winemaking and ageing: end of malolactic fermentation (point 3), 7 days after the third racking (point 11) and 6 months after bottling (point 13). As observed when considering each CIELAB parameter independently, results are clearly influenced by vintage and no clear trends can be observed. In 2010 vintage, after six months in bottle, the colour of Control wines and those of treated wines can be considered different $\left(\Delta E_{\mathrm{ab}}^{*}\right)$ (Martínez et al., 2001). Nevertheless, at this stage, no relevant colour differences could be observed between the different oenological treatments neither in 2010 nor 2009. 
Table 2

Colour differences $\left(\Delta E_{\mathrm{ab}}^{*}\right.$ ) between Control and treated wines and between treated wines in three sampling points (end of malolactic fermentation, 7 days after the third racking and 6 months after bottling) of 2009 and 2010 harvests.

\begin{tabular}{lcll}
\hline Sampling point & End of MLF (3) & $\begin{array}{l}\text { 7 days after } \\
\text { 3rd racking (11) }\end{array}$ & $\begin{array}{l}6 \text { months after } \\
\text { bottling (13) }\end{array}$ \\
\hline 2009 & & \\
Control vs. Overripe & $2.25 \pm 0.03$ & $4.04 \pm 0.01$ & - \\
$\quad \begin{array}{l}\text { Control vs. Tannin } \\
\text { Overripe vs. Tannin }\end{array}$ & $2.41 \pm 0.02$ & $1.88 \pm 0.07$ & - \\
2010 & & $2.41 \pm 0.08$ & $1.45 \pm 0.02$ \\
Control vs. Overripe & $2.4 \pm 0.1$ & $2.96 \pm 0.04$ & $3.63 \pm 0.04$ \\
Control vs. Tannin & $4.23 \pm 0.01$ & $0.90 \pm 0.04$ & $3.99 \pm 0.02$ \\
Overripe vs. Tannin & $2.1 \pm 0.1$ & $2.07 \pm 0.01$ & $0.55 \pm 0.01$ \\
\hline
\end{tabular}

A Principal Component Analysis (PCA) was performed with both the phenolic composition and the CIELAB colour results from each vintage in order to statistically verify the trends that were observed in the detailed analysis of each group of compounds. PCA have confirmed the results that have been extensively discussed in the manuscript (see supplementary files for PCA plots and additional comments).

\subsection{Additional considerations}

Colour is generally the first organoleptic property of the wine that is perceived by consumers and it is, therefore, responsible for the consumers' first opinion on a given wine. Colour changes with wine age and different hues are associated to the different stages of wine life. Young wines are expected to be redder than aged ones, which in turn are expected to show brick hues. Unexpected hues in a wine can even cause the initial rejection of that wine by consumers. Furthermore, colour may condition the perception of the aroma, taste or mouthfeel properties of a wine (Morrot et al., 2001; Österbauer et al., 2005). Thus, since the levels and proportions of the different pigments are responsible for the final colour of the wine, it can be said that anthocyanins and derivative pigments are key factors affecting the consumers' choice. Furthermore, as previously indicated other non-coloured phenolic compounds such as hydroxycinnamic acids can also affect wine colour through copigmentation reactions. On the other hand, bitterness and astringency are other key factors affecting wine acceptance by consumers. Flavanols seem to be the main compounds responsible for these organoleptic properties. Unbalanced wines, too bitter or astringent, or on the contrary, lacking tannic tones, or with "green" notes, etc... . are usually rejected by consumers. The type and levels of flavanols are, therefore, relevant for consumers' choice. The delay between technological and phenolic ripeness consequence of the global climate change affects wine quality and, therefore, acceptance of the wine by consumers. From the results of the present study it is possible to assess the usefulness of two oenological practices in lessening the negative impact on wine quality related to the delay between technological and phenolic ripeness. In relation to Control wines, Tannin wines, which were made from the same grapes collected at technological ripeness but with addition of oenological tannin during alcoholic fermentation, showed higher levels of total catechins and procyanidins and total gallocatechin and prodelphinidins and higher levels of monomeric and dimeric flavanols. It has been observed that the increase of the levels of these compounds was more noticeable when the levels are lower. Thus, respecting flavanols, the addition of the oenological tannin might be useful in increasing the flavanol content or in improving, in views of astringency and bitterness, the proportions of the different flavanols in wines elaborated with unripe grapes from a phenolic point of view. Respecting hydroxycinnamic acids and their tartaric esters, the oenological tannin employed in this study did not supply them to the wine but seemed to promote the release of the acids from their corresponding esters. However, differences in the levels between Tannin and Control wines decreased over time. Tannin wines also showed higher contents of anthocyanins monoglucosides than Control wines. Thus, the addition of the oenological tannin might be useful in wines made from grapes with low content of these pigments. Furthermore, the increase in the levels of the hydroxycinnamic acids might promote copigmentation reactions and modify wine colour. Respecting anthocyanin derivative pigments, the levels of flavanol-anthocyanin direct condensation products and Vitisin A were also higher in Tannin wines than in Control wines. Nevertheless, the addition of the oenological tannin barely affected the content of the vinylphenol derivative of Malvidin 3-O-glucoside. Tannin wines were darker (lower $L^{*}$ ) than Control wines, as a consequence of the higher phenolic content. However, no clear effect on chroma and hue was observed.

Wines elaborated with grapes harvested two weeks after technological ripeness have shown lower contents of total flavanols than Control wines, higher contents of caffeic, $p$ coumaric acids and, in some cases, higher contents of gallic, caftaric and coutaric acids. As Tannin wines, Overripe wines also showed higher levels of anthocyanins than Control wines, but whereas the former ones possessed the highest content in the earlier stages, Overripe wines showed the highest levels of anthocyanins (acylated and non-acylated) in the late stages which co-relates well with the highest values of chroma. Unlike Tannin wines, wines elaborated with overripe grapes showed the lowest content of Vitisin A and the highest of the Vinylphenol-Malvidin 3$O$-glucoside pyranoanthocyanin. Respecting flavanol-anthocyanin direct condensation products, in 2009 Overripe wines showed higher levels than Control and Tannin wines, but this effect was not observed in 2010, highlighting the differences between vintages for the same "overripe" state. Overripe wines were also darker than Control wines, but as in the case of Tannin wines no conclusions about the effect on chroma and hue could be drawn. From these results it seems that using overripe grapes might be useful above all when a stabilization of the colouring matter is required. To be precise, in Overripe wines not only is the anthocyanin content in the late stages increased in relation to Control and Tannin wines but also copigmentation reactions can be encouraged due to the increased levels of anthocyanins and hydroxycinnamic acids. Furthermore, the synthesis of derivative pigments is directed towards more stable pigments over time (Vinylphenol-Malvidin 3$O$-glucoside pyranoanthocyanin instead of Vitisin A).

\section{Conclusions}

The effect of 2 different oenological practices on levels and changes in levels of different classes of phenolic compounds was studied in wines made from Vitis vinifera L. cv Tempranillo grapes in two consecutive vintages. Differences in the phenolic composition of the wines made from the same grapes and with different oenological practices were observed. Nevertheless, for certain groups of compounds an important vintage effect was observed. Despite this vintage effect it was possible to evaluate the usefulness of these two oenological practices in lessening the negative effects on wine quality caused by the delay between technological and phenolic ripeness. The addition of the oenological tannin employed in this study during alcoholic fermentation will be useful in solving deficiencies in flavanol and pigment contents. On the contrary, the use of overripe grapes from a technological point of view will be useful above all when a stabilization of the colouring matter is required, since the contents 
of anthocyanins and hydroxycinnamic acids are increased and the synthesis of more stable anthocyanin derived pigments is promoted.

\section{Acknowledgements}

Thanks are due to the Spanish MICINN (Project ref. AGL201130254-C02-01) and to the OIV for financial support. I. GarcíaEstévez thanks the Spanish MICINN for the F.P.U. predoctoral scholarship. The authors also thank Bodegas RODA S.A. (Haro, La Rioja, Spain) and Bodegas La Horra (La Horra, Castilla y León,Spain) for supplying the wine samples.

\section{Appendix A. Supplementary data}

Supplementary data associated with this article can be found, in the online version, at http://dx.doi.org/10.1016/j.jfca.2014.01.004.

\section{References}

Alcalde-Eon, C., Escribano-Bailón, M.T., Santos-Buelga, C., Rivas-Gonzalo, J.C., 2006 Changes in the detailed pigment composition of red wine during maturity and ageing. A comprehensive study. Analytica Chimica Acta 563, 238-254.

Asenstorfer, R.E., Markides, A.J., Iland, P.G., Jones, G., 2003. Formation of vitisin A during red wine fermentation and maturation. Australian Journal of Grape and Wine Research 9, 40-46.

Bacon, J.R., Rhodes, M.J.C., 1998. Development of a competition assay for the evaluation of the binding of human parotid salivary proteins to dietary complex phenols and tannins using a peroxidase-labeled tannin. Journal of Agricultural and Food Chemistry 46, 5083-5088.

Bautista-Ortín, A.B., Fernández-Fernández, J.I., López-Roca, J.M., Gómez-Plaza, E., 2006. The effect of grape ripening stage on red wine color. Journal International de la Science de la Vigne et du Vin 40, 14-24.

Bautista-Ortín, A.B., Fernández-Fernández, J.I., López-Roca, J.M., Gómez-Plaza, E. 2007. The effects of enological practices in anthocyanins, phenolic compounds and wine colour and their dependence on grape characteristics. Journal of Food Composition and Analysis 20, 546-552.

Boulton, R., 2001. The copigmentation of anthocyanins and its role in the color of red wine: a critical review. American Journal of Enology and Viticulture 52, 67-87.

Cabrita, M.J., Torres, M., Palma, V., Alves, E., Patão, R., Costa Freitas, A.M., 2008 Impact of malolactic fermentation on low molecular weight phenolic compounds. Talanta 74, 1281-1286.

Cadot, Y., Miñana-Castelló, M.T., Chevalier, M., 2006. Anatomical, histological, and histochemical changes in grape seeds from Vitis vinifera L. cv Cabernet franc during fruit development. Journal of Agricultural and Food Chemistry 54, 9206 9215.

Canals, R., Llaudy, M.C., Valls, J., Canals, J.M., Zamora, F., 2005. Influence of ethanol concentration on the extraction of color and phenolic compounds from the skin and seeds of Tempranillo grapes at different stages of ripening. Journal of Agricultural and Food Chemistry 53, 4019-4025.

Darias-Martín, J., Carrillo, M., Díaz, E., Boulton, R.B., 2001. Enhancement of red wine colour by pre-fermentation addition of copigments. Food Chemistry 73 , 217-220.

Ferrer-Gallego, R., García-Marino, M., Henández-Hierro, J.M., Rivas-Gonzalo, J.C., Escribano-Bailón, M.T., 2010. Statistical correlation between flavanolic composition, colour and sensorial parameters in grape seed during ripening. Analytica Chimica Acta 660, 22-28

Ferrer-Gallego, R., Hernández-Hierro, J.M., Rivas-Gonzalo, J.C., Escribano-Bailón M.T., 2011. Multivariate analysis of sensory data of Vitis vinifera L. cv Graciano during ripening. Correlation with the phenolic composition of the grape skins. CyTA - Journal of Food 9, 290-294.

Ferrer-Gallego, R., Hernández-Hierro, J.M., Rivas-Gonzalo, J.C., Escribano-Bailón, M.T., 2012. Influence of climatic conditions on the phenolic composition of Vitis vinifera L cv.Graciano. Analytica Chimica Acta 732, 73-77.

Fournand, D., Vicens, A., Sidhoum, L., Souquet, J.-M., Moutounet, M., Cheynier, V. 2006. Accumulation and extractability of grape skin tannins and anthocyanins at different advanced physiological stages. Journal of Agricultural and Food Chemistry 54, 7331-7338.

Fulcrand, H., Cameira dos Santos, P.J., Sarni-Manchado, P., Cheynier, V., FavreBonvin, J., 1996. Structure of new anthocyanin-derived wine pigments. Journal of the Chemical Society, Perkin Transactions 1, 735-739.

García-Marino, M., Rivas-Gonzalo, J.C., Ibáñez, E., García-Moreno, C., 2006. Recovery of catechins and proanthocyanidins from winery by-products using subcritical water extraction. Analytica Chimica Acta 563, 44-50.

García-Puente Rivas, E., Alcalde-Eon, C., Santos-Buelga, C., Rivas-Gonzalo, J.C., Escribano-Bailón, M.T., 2006. Behaviour and characterisation of the colour during red wine making and maturation. Analytica Chimica Acta 563, 215-222.
Gil, M., Kontoudakis, N., González, E., Esteruelas, M., Fort, F., Canals, J.M., Zamora, F. 2012. Influence of grape maturity and maceration length on color, polyphenolic composition, and polysaccharide content of Cabernet Sauvignon and Tempranillo wines. Journal of Agricultural and Food Chemistry 60, 7988-8001.

Ginjom, I., D’Arcy, B., Caffin, N., Gidley, M., 2011. Phenolic compound profiles in selected Quensland red wines at all stages of the wine-making process. Food Chemistry 125, 823-834.

González-Manzano, S., Rivas-Gonzalo, J.C., Santos-Buelga, C., 2004. Extraction of flavan-3-ols from grape seed and skin into wine using simulated maceration. Analytica Chimica Acta 513, 283-289.

González-Manzano, S., Santos-Buelga, C., Pérez-Alonso, J.J., Rivas-Gonzalo, J.C. Escribano-Bailón, M.T., 2006. Characterization of the mean degree of polymerization of proanthocyanidins in red wines using liquid chromatography-mass spectrometry (LC-MS). Journal of Agricultural and Food Chemistry 54, 43264332.

González-Manzano, S., Dueñas, M., Rivas-Gonzalo, J.C., Escribano-Bailón, M.T. Santos-Buelga, C., 2009. Studies on the copigmentation between anthocyanins and flavan-3-ols and their influence in the colour expression of red wine. Food Chemistry 114, 649-656.

Harbertson, J.F., Parpinello, G.P., Heymann, H., Downey, M.O., 2012. Impact of exogenous tannin additions on wine chemistry and wine sensory character. Food Chemistry 131, 999-1008.

Heredia, F.J., Álvarez, C., González-Miret, M.L., Ramirez, A., 2004. CromaLab Análisis de Color; Registro General de la Propiedad Intelectual SE-1052-04: Sevilla, Spain.

Hernández, T., Estrella, I., Pérez-Gordo, M., Alegría, E.G., Tenorio, C., Ruiz-Larrea, F., Moreno-Arribas, M.V., 2007. Contribution of malolactic fermentation by Oenococcus Oeni and Lactobacillus Plantarum to the changes in the nonanthocyanin polyphenolic composition of red wine. Journal of Agricultural and Food Chemistry $55,5260-5266$.

Hernández-Hierro, J.M., Quijada-Morín, N., Rivas-Gonzalo, J.C., Escribano-Bailón, M.T., 2012. Influence of the physiological stage and the content of soluble solids on the anthocyanin extractability of Vitis vinifera L. cv Tempranillo grapes. Analytica Chimica Acta 732, 26-32.

Jones, G.V., White, M.A., Cooper, O.R., Storchmann, K., 2005. Climate change and global wine quality. Climatic Change 73, 319-343.

Kennedy, J.A., Matthews, M.A., Waterhouse, A.L., 2000. Changes in grape seed polyphenols during fruit ripening. Phytochemistry 55, 77-85.

MAGRAMA, 2009. Encuesta base de viñedo 2009. Ministerio de agricultura, ali mentación y medioambiente. Retrieved October 15, 2012 from: http://www.magrama.gob.es/es/estadistica/temas/estadisticas-agrarias/Viñedo2009web tcm7207640.pdf.

Malheiro, A.C., Santos, J.A., Fraga, H., Pinto, J.G., 2010. Climate change scenarios applied to viticultural zoning in Europe. Climate Research 43, 163-177.

Martínez, J.A., Melgosa, M., Pérez, M.M., Hita, E., Negueruela, A.I., 2001. Note. Visual and instrumental color evaluation in red wines. Food Science and Technology International 7, 439-444.

Martínez-Pinilla, O., Martínez-Lapuente, L., Guadalupe, Z., Ayestarán, B., 2012. Sensory profiling and changes in colour and phenolic composition produced by malolactic fermentation in red minority varieties. Food Research International 46, 286-293.

Mira de Orduña, R., 2010. Climate change associated effects on grape and wine quality and production. Food Research International 43, 1844-1855.

Moreno-Rodríguez, J.M., 2005. Main conclusions from the preliminary assessment of the impacts in Spain due to the effects of climate change. Project ECCE, Ministry of the Environment and University of Castilla-La Mancha. Retrieved October 15, 2012 from: http://www.magrama.gob.es/es/cambio-climatico temas/impactos-vulnerabilidad-y-adaptacion/full_report_tcm7-199440.pdf.

Morrot, G., Brochet, F., Dubourdieu, D., 2001. The color of odors. Brain and Language 79, 309-320.

Ortega-Regules, A., Romero-Cascales, I., Ros-García, J.M., López-Roca, J.M., GómezPlaza, E., 2006. A first approach towards the relationship between grape skin cell-wall composition and anthocyanin extractability. Analytica Chimica Acta $563,26-32$.

Österbauer, R.A., Matthews, P.M., Jenkinson, M., Beckmann, C.F., Hansen, P.C., Calvert, G.A., 2005. Color of scents: chromatic stimuli modulate odor responses in the human brain. Journal of Neurophysiology 93, 3434-3441.

Parker, M., Smith, P.A., Birse, M., Francis, I.L., Kwiatkowski, M.J., Lattey, K.A., Liebich, B., Herderich, M.J., 2007. The effect of pre- and post-ferment additions of grape derived tannin on Shiraz wine sensory properties and phenolic composition. Australian Journal of Grape and Wine Research 13, 30-37.

Pérez-Magariño, S., González-San José, M.L., 2006. Polyphenols and colour variability of red wines made from grapes harvested at different ripeness grade. Food Chemistry 96, 197-208.

Quijada-Morín, N., Dangles, O., Rivas-Gonzalo, J.C., Escribano-Bailón, M.T., 2010. Physico-chemical and chromatic characterization of malvidin 3-glucosidevinylcatechol and malvidin 3-glucoside-vinylguaiacol wine pigment. Journal of Agricultural and Food Chemistry 58, 9744-9752.

Ramos, M.C., Jones, G.V., Martínez-Casasnovas, J.A., 2008. Structure and trends in climate parameters affecting winegrape production in northeast Spain. Climate Research 38, 1-15.

Ribéreau-Gayon, P., Glories, Y., Maujean, A., Dubourdieu, D., 2000. Handbook of Enology, Volume 2: The Chemistry of Wine and Stabilization and Treatments. John Wiley \& Sons, Chichester, England.

Río Segade, S., Soto-Vázquez, E., Díaz-Losada, E., 2008. Influence of ripeness grade on accumulation and extractability of grape skin anthocyanins in different cultivars. Journal of Food Composition and Analysis 21, 599-607. 
Río Segade, S., Giacosa, S., Gerbi, V., Rolle, L., 2010. Berry skin thickness as main texture parameter to predict anthocyanin extractability in wine grapes. LWTFood Science and Technology 44, 392-398.

Salazar-Parra, C., Aguirreolea, J., Sánchez-Díaz, M., Irigoyen, J.J., Morales, F., 2010. Effects of climate change scenarios on Tempranillo grapevine (Vitis vinifera L.) ripening: response to a combination of elevated $\mathrm{CO}_{2}$ and temperature and moderate drought. Plant Soil 337, 179-191.

Schwarz, M., Wabnitz, T.C., Winterhalter, P., 2003. Pathway leading to the formation of anthocyanin-vinylphenol adducts and related pigments in red wines. Journal of Agricultural and Food Chemistry 51, 3682-3687.
Sweetman, C., Deluc, L.G., Cramer, G.C., Ford, C.M., Soole, K.L., 2009. Regulation of malate metabolism in grape berry and other developing fruits. Phytochemistry $70,1329-1344$

Torchio, F., Cagnasso, E., Gerbi, V., Rolle, L., 2010. Mechanical properties, phenolic composition and extractability indices of Barbera grapes of different soluble solids contents from several growing areas. Analytica Chimica Acta 660, 183-189.

Vivas, N., Glories, Y., 1996. Role of oak wood ellagitannins in the oxidation process of red wines during aging. American Journal of Enology and Viticulture 47, 103-107. 